\title{
CHAPTER 3 Organocatalytic transfer hydrogenation and hydrosilylation reactions
}

\section{Raquel P. Herrera}

\begin{abstract}
The reduction of different carbon-carbon or carbon-heteroatom double bonds is a powerful tool that generates in many cases new chiral centers. In the last decade, the organocatalytic version of these transformations has attracted more attention, and remarkable progresses have been made in this way. Organocatalysts such as chiral Brønsted acids, thioureas, chiral secondary amines or Lewis bases have been successfully used for this purpose. In this context, this chapter will cover pioneering and seminal examples using Hantzsch dihydropyridines $\mathbf{1}$ and trichlorosilane $\mathbf{2}$ as reducing agents. More recent examples will be also cited in order to cover as much as possible the complete research in this field.
\end{abstract}

Key words transfer hydrogenation, organocatalysis, Hantzsch ester, trichlorosilane, phosphoric acid, aminocatalysis, thioureas, Lewis bases, reduction, hydrosilylation.

\subsection{Introduction}

The reduction of different carbon-carbon or carbon-heteroatom double bonds is an important transformation that generates in many cases new chiral centers. Particularly, the asymmetric reduction of prochiral ketimines represents one of the most important methods and straightforward procedures for preparing chiral amines. This approach is one of the key reactions and powerful tool in synthetic organic chemistry, which provides precious building blocks for natural products, pharmaceutical and other fine chemical industries.[1] Until last decade, available chemical catalysts for the enantioselective reduction of these substrates were mostly limited to chiral transition metal complexes, which often required elevated pressures and/or the use of additional additives to afford high yields and ee values.[2] However, with the increasing interest during the last years in the development of the organocatalysis field,[3] the 
organocatalytic version of these transformations has attracted more attention, and remarkable progresses have been made in this way.[4] The organocatalytic transfer hydrogenation is carried out by four fundamentally different approaches (Figure 3.1): (i) reduction with Hantzsch dihydropyridines 1, mainly catalyzed by chiral Brønsted acids, which activate the electrophilic substrates;[5] (ii) hydrosilylation with trichlorosilane 2, catalyzed through chiral Lewis-bases, which, in contrast, activate the nucleophilic hydride source;[6] and more recently, (iii) transfer hydrogenation using benzothiazolines $\mathbf{3}$ as the reducing agent[7,8] and (iv) hydrogen activation by frustrated Lewis pair 4.[9]<smiles>[R]OC(=O)C1=C(C)NC(C)=C(C(=O)O[R])C1</smiles>

1a $\mathrm{R}=\mathrm{Me}$

$1 \mathrm{~b} R=\mathrm{Et}$

1c $\mathrm{R}=t \mathrm{Bu}$

1d $\mathrm{R}=$ Allyl

1e $\mathrm{R}=i \mathrm{Pr}$<smiles>[SiH3]</smiles>

2<smiles>[R]C1Nc2ccccc2S1</smiles>

3<smiles>CC(C)(C)[PH2]C(C)(C)C</smiles>

Figure 3.1 Model reducing agents.

Interestingly, $\mathbf{1 a - c}$ and $\mathbf{2}$ are commercially available, while $\mathbf{1 d - e}$ must be synthesized, being $\mathbf{2}$ cheaper than the others and being 1a the most expensive one. Trichlorosilane $\mathbf{2}$ has shown a great spectrum of reactivity, as the reader could found in the second part of this chapter.

Although this field has been extensively reported, only pioneering and seminal examples using Hantzsch dihydropyridines $\mathbf{1}$ and trichlorosilane 2, as reducing agents, will be disclosed in this chapter. More recent examples will be also cited in order to cover as much as possible the complete research in this field.

\subsection{Hantzsch esters as hydride source}

Inspired by the nature and trying to reproduce the enzymatic reductions using $\mathrm{NAD}(\mathrm{P}) \mathrm{H}$ as cofactor in living organisms, many research groups have focused part of their investigation in the development of new environmentally friendly and successful reducing agents trying to simulate its reactivity. That is the case of Hantzsch esters 1 as hydride source,[10] which were initially synthesized following a multicomponent approach as an interesting synthetic example 
of 1,4-dihydropyridines. Although, it was only in the last decade when Hantzsch esters $\mathbf{1}$ became a key piece in the reduction processes using organocatalysts, the first reported example of transfer hydrogenation using this hydride source without metals is dated in 1989.[11,12] In the next pages, the pioneering enantioselective examples using Hantzsch dihydropyridines $\mathbf{1}$ in organocatalysis and the most recent advances in this subarea of research will be briefly covered.

\subsubsection{Chiral phosphoric acid catalyzed transfer hydrogenation}

The reduction of imines is potentially useful for the synthesis of enantiomerically pure amines, since chiral amines appear in numerous interesting compounds in nature and it is also remarkable their use as ligands in metal catalysis or as chiral organocatalysts. However, until 2001 this approach had been mainly explored using metal catalysts.[2]

The first enantioselective Brønsted acid-catalyzed transfer hydrogenation of ketimines using Hantzsch ester 1b was reported by Rueping's[13] (Scheme 3.1) and, independently, by List's groups (Scheme 3.2)[14] affording excellent results in terms of enantioselectivity and reactivity and in both cases using chiral phosphoric acid derivatives 6 and 9. Interestingly, in the latter case the authors significantly improved the results employing 20 -fold reduction in the catalyst loading.
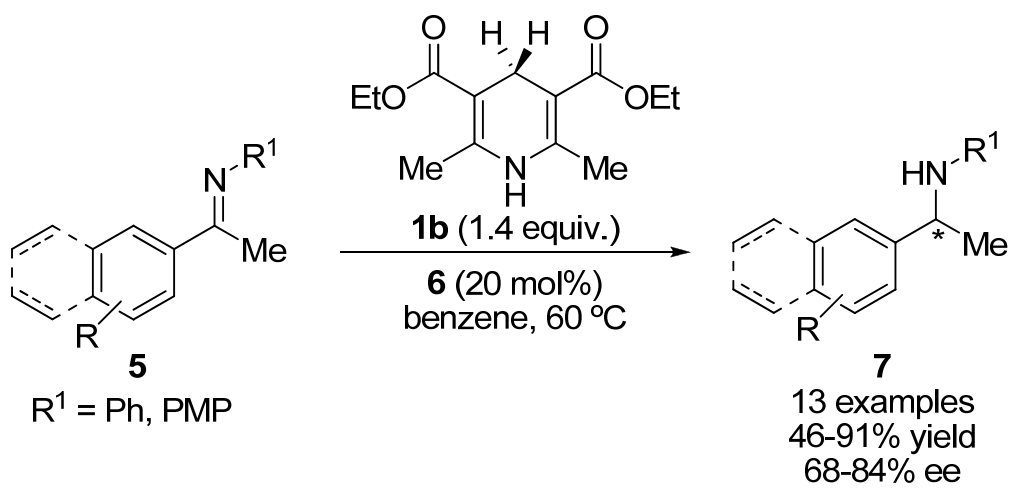<smiles>O=P(O)(O)Oc1cc2ccccc2cc1-c1c(OP(=O)(O)Oc2ccccc2)c(Br)cc2ccccc12</smiles>

Scheme 3.1 Reduction of imines using phosphoric acid $\mathbf{6}$ as catalyst. 
<smiles>[R]C([18OH])=N[Pb]</smiles>

$\mathrm{R}=$ Aryl, Alkyl<smiles>CCOC(=O)C1=C(C)NC(C)=C(C(=O)OCC)[CH]1</smiles>

10

11 examples $80-98 \%$ yield $80-93 \%$ ee

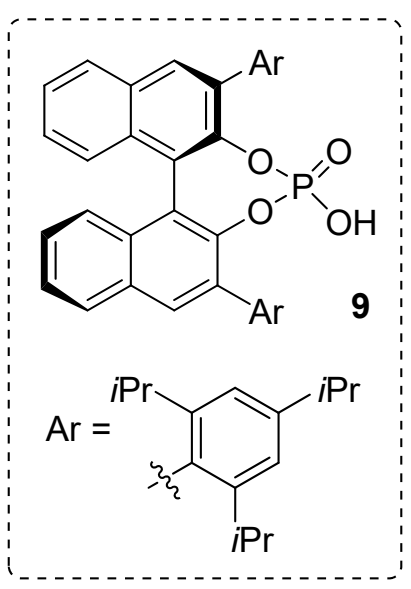

Scheme 3.2 Reduction of imines using Brønsted acid 9 as catalyst.

Based on previous studies where the imines were reduced with Hantzsch dihydropyridines in the presence of achiral Lewis[15] or Brønsted acid catalysts,[16] joined to the capacity of phosphoric acids to activate imines,[17] the authors proposed a reasonable catalytic cycle to explain the course of the reaction (Scheme 3.3).[13] A first protonation of the ketimine with the chiral Brønsted acid catalyst would initiate the cycle. The resulting chiral iminium ion pair $\mathbf{A}$ would react with the Hantzsch ester $\mathbf{1 b}$ giving an enantiomerically enriched amine product and the protonated pyridine salt $\mathbf{B}$ (Scheme 3.3). The catalyst is finally recovered and the byproduct $\mathbf{1 1}$ is obtained in the last step. Later, other research groups also supported this mechanism.[18] 


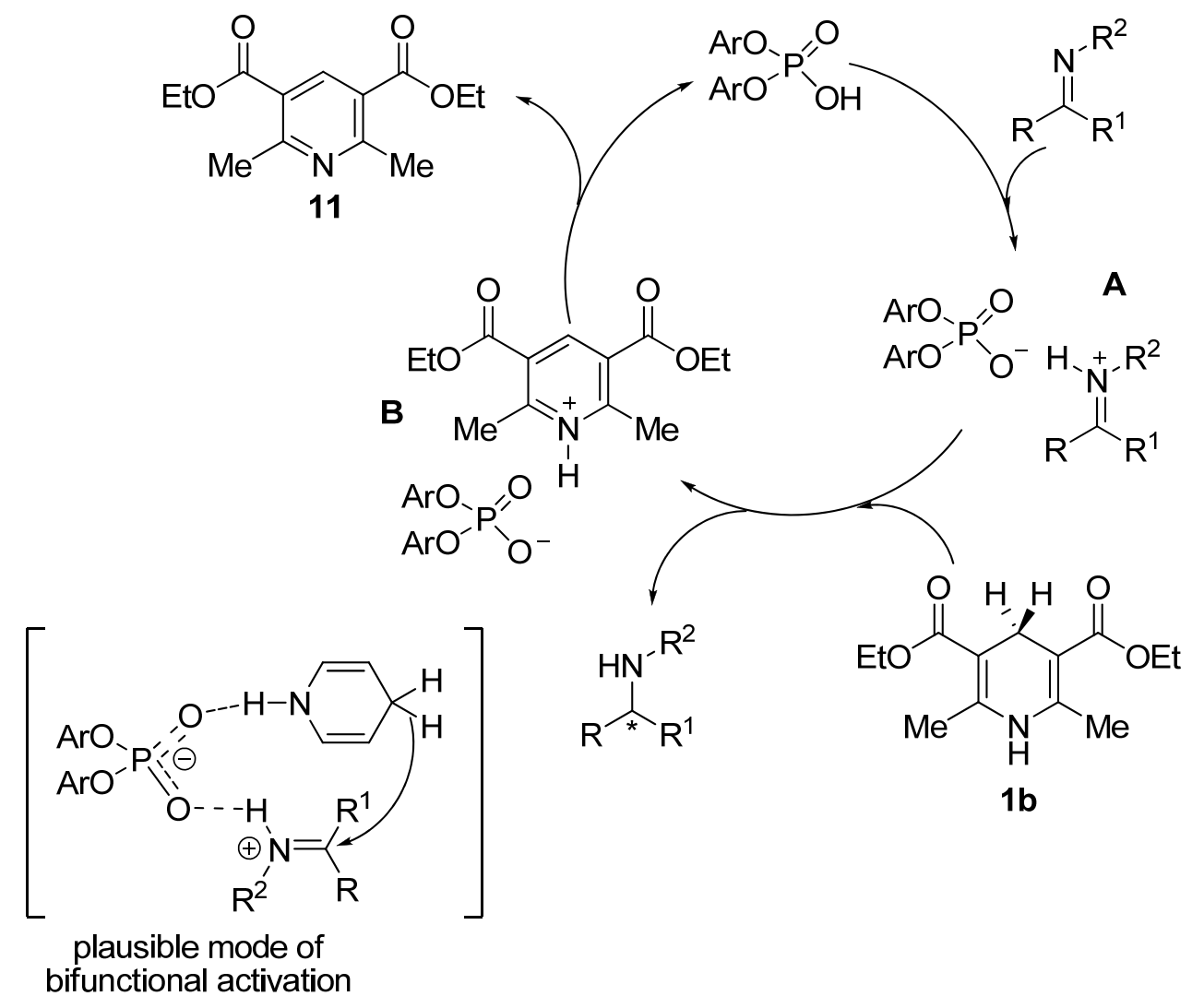

Scheme 3.3 Proposed catalytic cycle for the reduction of ketimines.

Since these seminal organocatalytic reports, other groups have used the same strategy for the reduction of different interesting imine derivatives such as MacMillan,[19,20] You[21,22] and Antilla.[23]

Because of the importance of chiral nitrogen on heterocycles constituting the structural core of many natural alkaloids and synthetic drugs, a great extension of this protocol has been performed during the last decade mainly by Rueping's group, affording different and valuable chiral heterocyclic products. In the next pages some pivotal examples reported by this research group will be disclosed and commented.

Thus, Rueping and co-workers used their abovementioned methodology for the interesting activation of quinolines $\mathbf{1 2}$ by catalytic protonation and subsequent transfer hydrogenation, which involved a 1,4-hydride addition, isomerization, and final 1,2-hydride addition to generate the desired 1,2,3,4-tetrahydroquinolines $\mathbf{1 4}$ in a cascade process (Scheme 3.4).[24] These compounds have proven to be interesting synthetic scaffolds in the preparation of pharmaceuticals and agrochemicals.[25] In this context, and having developed a general and 
enantioselective protocol, the authors demonstrated the applicability of this new methodology to the synthesis of biologically active tetrahydroquinoline alkaloids: galipinine $\mathbf{1 5 a},[26]$ cuspareine $\mathbf{1 5 b},[26 b, 27]$ and angustureine 15c[26b] (Scheme 3.4).[28,29]

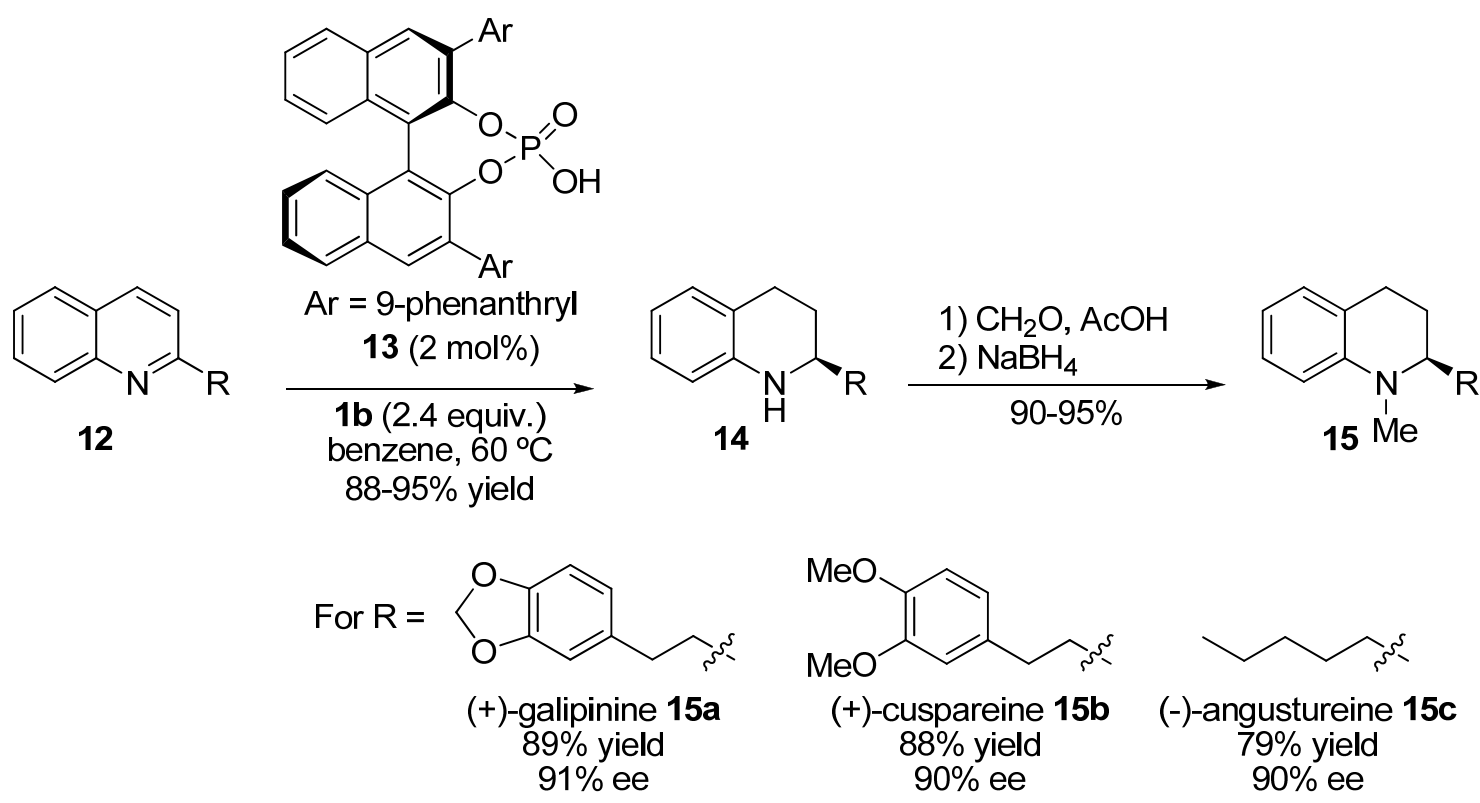

Scheme 3.4 Syntheses of biologically active tetrahydroquinoline alkaloids $\mathbf{1 5}$.

Biologically active tetrahydroquinoline alkaloids 15 were prepared by simple $N$-methylation of intermediates 14 to lead the desired natural products in good overall yields and high enantioselectivities.[30,31]

To explain the obtained products, the authors hypothesized that the first step should be the protonation of the quinoline $\mathbf{1 2}$ through the phosphoric acid catalyst $\mathbf{1 3}$ to generate the iminium ion $\mathbf{A}$ (Scheme 3.5). Transfer of a first hydride from the dihydropyridine $\mathbf{1 b}$ would generate the enamine intermediate $\mathbf{1 6}$ and pyridinium salt $\mathbf{B}$, which would regenerate the acid catalyst $\mathbf{1 3}$ and release pyridine 11. The enamine $\mathbf{1 6}$ would interact with another molecule of Brønsted acid $\mathbf{1 3}$ to produce iminium $\mathbf{C}$, which would receive the attack of a second molecule of hydride giving rise the desired tetrahydroquinoline 14. Subsequent proton transfer would recycle again the Brønsted catalyst 13 and would generate a second equivalent of pyridine 11. (Scheme 3.5) 


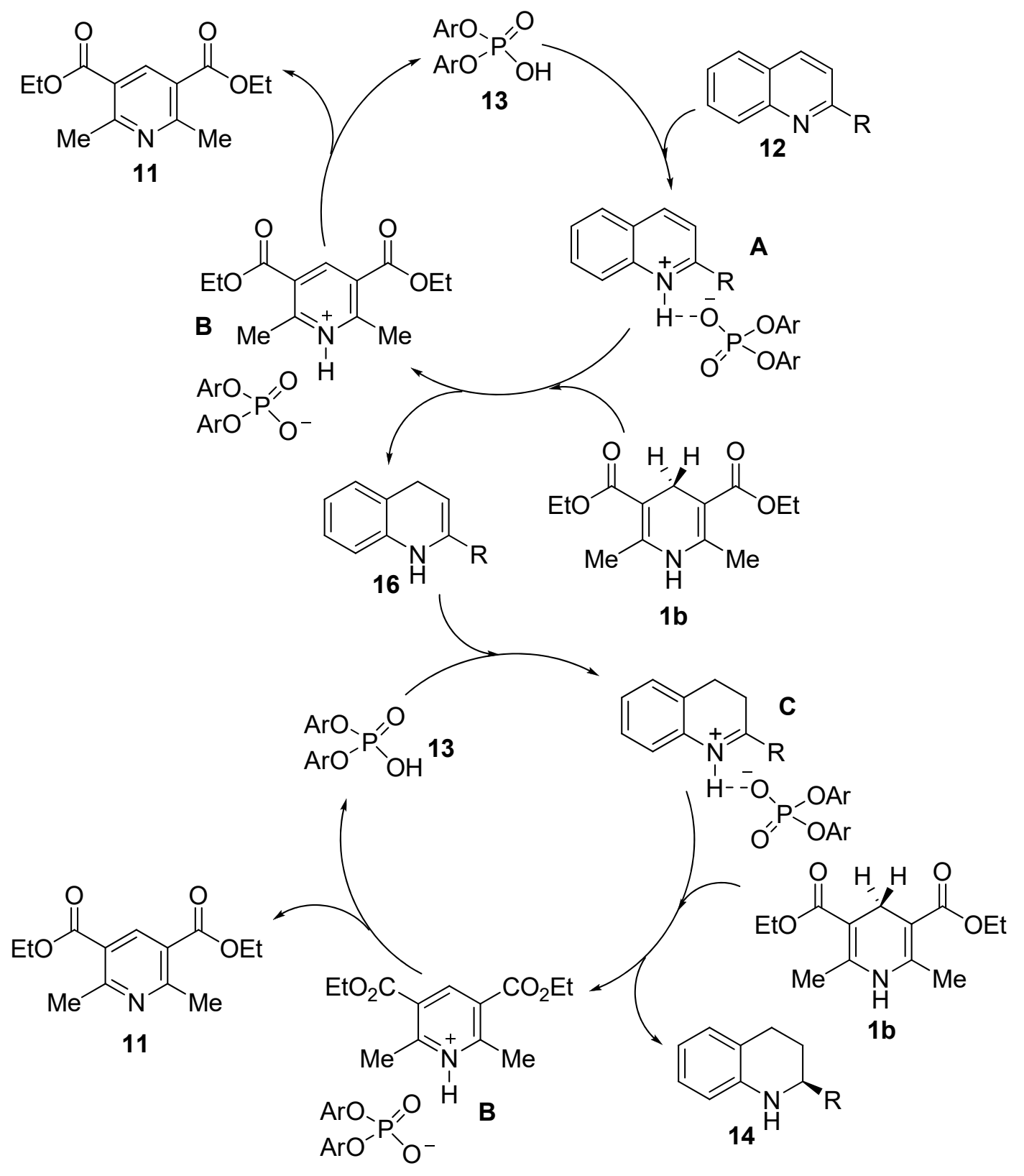

Scheme 3.5 Mechanism for the cascade transfer hydrogenation of quinolines $\mathbf{1 2}$.

The reduction of quinolines was applied to the asymmetric preparation of the anti-bacterial agent $(R)$-flumequine 18,[32] starting from quinoline 12a and generating the key tetrahydroquinoline intermediate 14a for the total synthesis and using $\mathbf{1 7}$ as catalyst (Scheme 3.6).[33] 


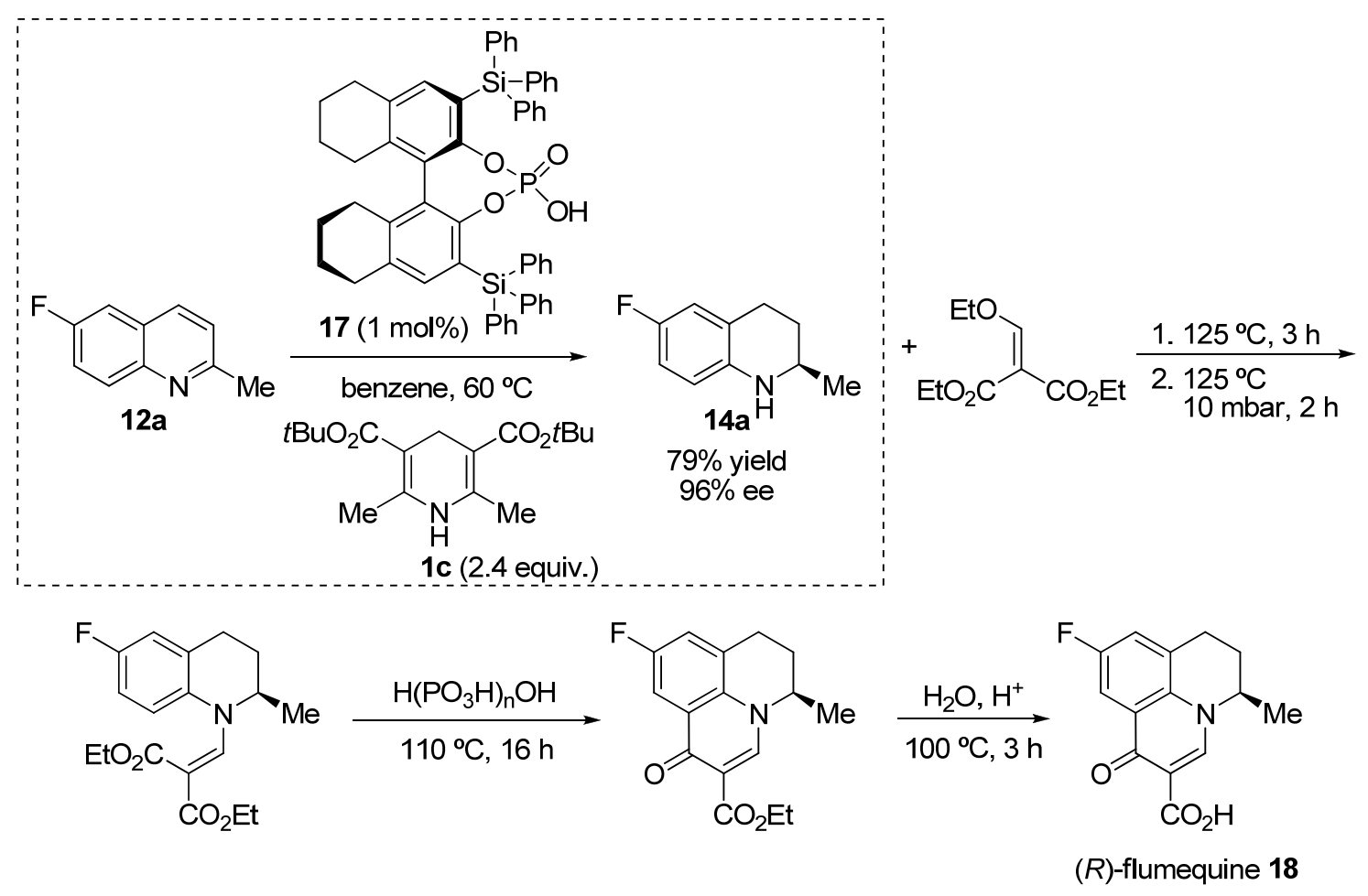

Scheme 3.6 Synthesis of $(R)$-flumequine 18.

Gong and co-workers developed the first step-economical synthesis of the previous described process. The approach involves a Friedländer condensation[34] followed by a transfer hydrogenation catalyzed by a combination of an achiral Lewis acid and a chiral Brønsted acid. This affords the direct conversion of 2-aminobenzaldehyde derivatives 19 and ketones $\mathbf{2 3}$ into highly optically active 1,2,3,4-tetrahydroquinoline derivatives $\mathbf{2 2}$ and $\mathbf{2 4}$, with enolizable dicarbonyl compounds $\mathbf{2 0}$ (Scheme 3.7).[35] 
<smiles>[NH3+]c1cc[R1]cc1C=O</smiles>

19<smiles>[R]C(=O)CC(=O)OCC</smiles>

20<smiles>CC(=O)C1=C(C)NC(C(C)=O)=C(C(C)=O)C1</smiles>

$1 a$

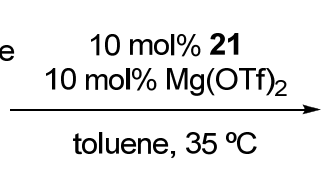

(O)<smiles>[R]C1Nc2cc[R11](CC)cc2C[C@@H]1C(=O)OCC</smiles>

13 examples $55-91 \%$ yield 90-97\% ee<smiles>[R]C(=O)c1c[R1]ccc1N</smiles>

23<smiles>CCOC(=O)CC(C)=O</smiles>

20a<smiles>COC(=O)C1=C(C(C)=O)NC(C)=C(C(C)=O)C1</smiles>

1a

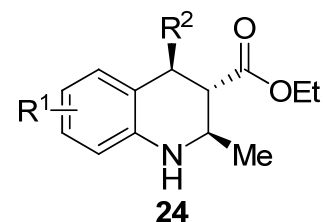

8 examples $64-97 \%$ yield $85-98 \%$ ee d.r. $>20: 1$

Scheme 3.7 Step-economical syntheses of tetrahydroquinolines 22 and $\mathbf{2 4}$.

The Lewis acid (LA) is believed to only participate in the catalyzed Friedländer condensation, while the chiral phosphoric acid $\left(\mathrm{B}^{*}-\mathrm{H}\right)$ could participate in the first condensation to give $\mathbf{2 5}$ and in the asymmetric transfer hydrogenation of $\mathbf{A}$ (Scheme 3.8). The success of this approach relies in the compatibility and synergic effect of both catalysts, the Lewis acid and the chiral Brønsted acid.<smiles>[R17]CCCCCCCCCCC(=O)C[R]</smiles>

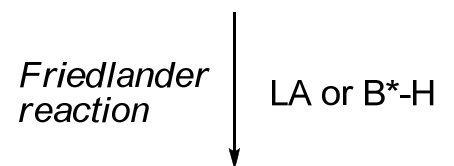<smiles>[R]c1nc2cc[R11]cc2c([R])c1[R]</smiles>

25

Neither workup nor isolation required

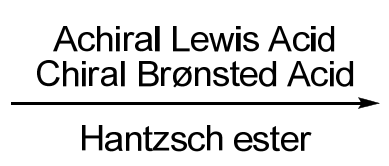<smiles>[R1]c1ccc2[nH]c([R])c([R])c2c1[R]</smiles>

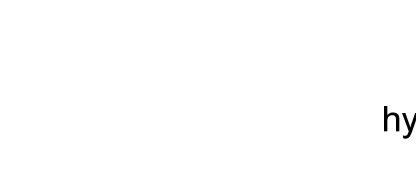


Scheme 3.8 Proposed mechanism.

Rueping's group pioneered the first example of a catalyzed enantioselective reduction of pyridines giving rise direct access to enantiomerically pure piperidines 26 (Figure 3.2).[36]
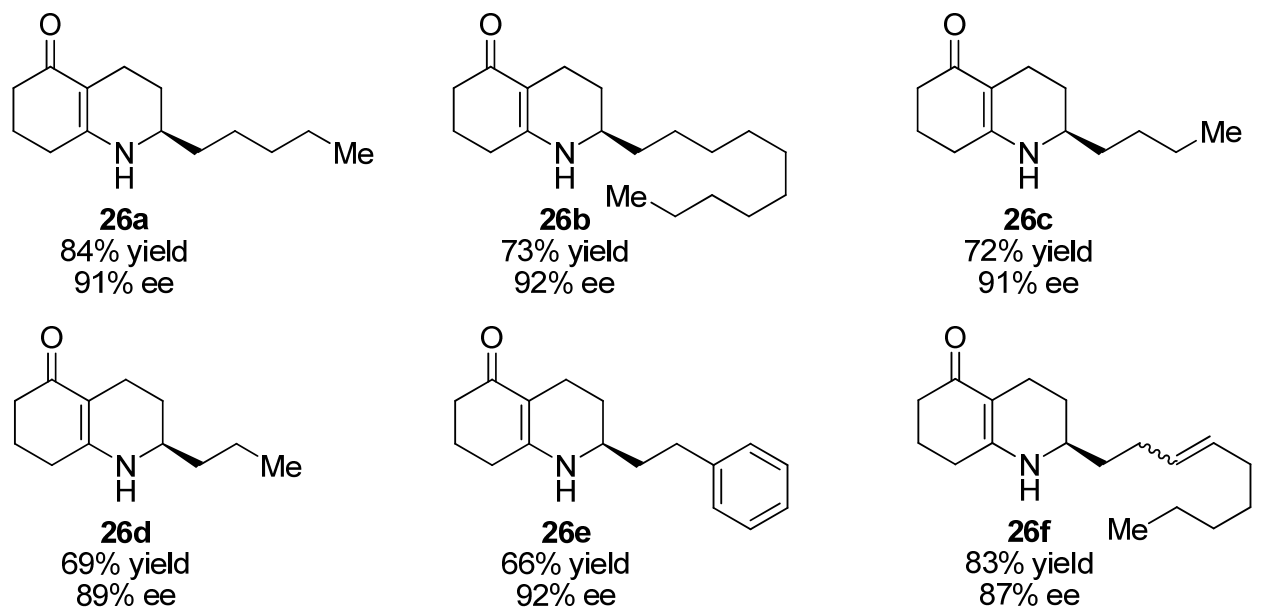<smiles>CCCCCC1CCC(C#N)=C(C)N1</smiles>

26g

$73 \%$ yield<smiles>CCCCC1CCC(C#N)=C(C)N1</smiles>

26h

$55 \%$ yield $84 \%$ ee<smiles>CC1=C(C#N)CCC(CCc2ccccc2)N1</smiles>

26i $47 \%$ yield $86 \%$ ee

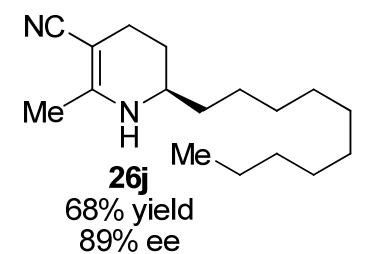

Figure 3.2 Scope of reduction of pyridines.

The applicability of this new method was demonstrated in the formal synthesis of diepipumiliotoxin C 31 from the pumiliotoxin family (Scheme 3.9).[36] Hence, the reduction of pyridine 29a, which can be readily prepared according to Bohlmann and Rahtz's procedure starting from 27 and 28,[37] gives the corresponding (S)-2-propylhexahydroquinolinone 30a as a key intermediate for the subsequent transformation (Scheme 3.9).[38]<smiles>[NH3+]C1=CC(=O)CCC1</smiles>

27<smiles>C#CC(=O)CCC</smiles>

28
1) $\mathrm{EtOH}, 50^{\circ} \mathrm{C}, 12 \mathrm{~h}$

2) $140^{\circ} \mathrm{C}, 2 \mathrm{~h}$<smiles>[M]CCc1ccc2c(n1)CCCC2=O</smiles>

29a

$$
\underset{\begin{array}{c}
1 \mathrm{~b}(4 \text { equiv. }) \\
\text { benzene, } 500^{\circ} \mathrm{C}
\end{array}}{\stackrel{21(5 \mathrm{~mol} \%)}{\longrightarrow}}
$$<smiles>O=P(O)(Oc1ccccc1)Oc1c(Br)cc2ccccc2c1-c1cc2ccccc2cc1Br</smiles>

(S)-2-propylhexahydroquinolinone $30 a$<smiles>CC(C)(C)Br</smiles>

diepi-pumiliotoxin C 31

Scheme 3.9 Formal synthesis of diepi-pumiliotoxin C 31. 
A plausible mechanism of the reduction was also proposed to explain the final products. Thus, in the first step, the pyridines $\mathbf{2 9}$ would be activated through catalytic protonation by the phosphoric acid catalyst 21, resulting in the formation of a chiral ion pair $\mathbf{A}$ (Scheme 3.10). A subsequent hydride transfer from the Hantzsch ester $\mathbf{1 b}$ would afford adduct $\mathbf{B}$, which would be transformed into the iminium ion $\mathbf{C}$ through an isomerization. A second hydride transfer would render the desired product $\mathbf{2 6}$ or $\mathbf{3 0}$, and $\mathbf{2 1}$ would be regenerated (Scheme 3.10).

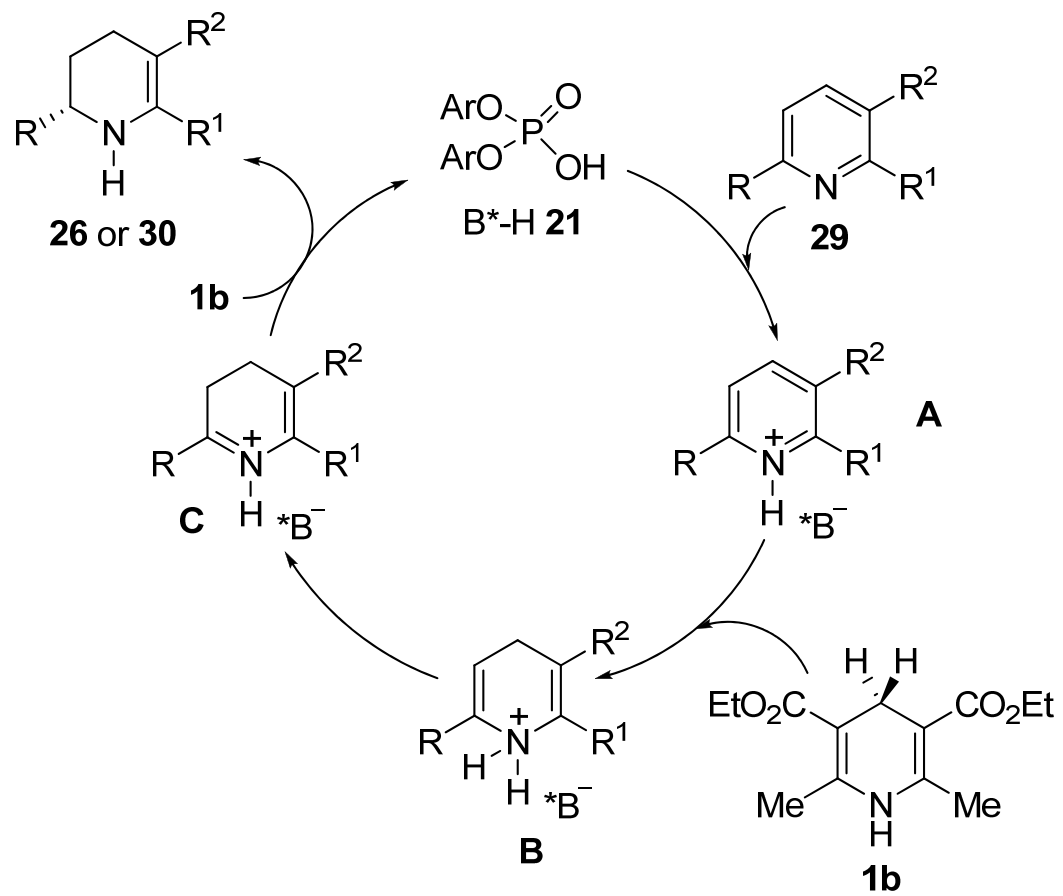

Scheme 3.10 Mechanism proposal giving rise to piperidines $\mathbf{2 6}$ and $\mathbf{3 0}$.

The same research group developed a similar protocol for the reduction of benzoxazines $\mathbf{3 2}$, benzothiazines $\mathbf{3 3}$ and benzoxazinones $\mathbf{3 4}$ as key examples of heterocyclic compounds (Figure 3.3).[39]<smiles>BrC1=Nc2ccccc2OC1</smiles>

32 benzoxazines<smiles>[Al]C1=Nc2ccccc2SC1</smiles>

33<smiles>O=c1oc2ccccc2nc1[Al]</smiles>

34

benzothiazines benzoxazinones

Figure 3.3 Model heteroaromatic compounds reduced.

With the increasing interest experienced by enantioselective domino reactions as powerful tools for the direct construction of enantioenriched complex targets starting from simple and readily 
available precursors, many investigations have been developed in this area of research, where the organocatalysis has gained an important position.[40]

In this context, Rueping's group envisioned the asymmetric organocatalytic multiple-reaction cascade version of the abovementioned process in which a six-step sequence was catalyzed by the chiral Brønsted acid catalyst $\mathbf{2 1}$ providing direct access to a broad scope of valuable tetrahydropyridines $\mathbf{2 6}$ and azadecalinones 35 with high enantioselectivities (Scheme 3.11).[41]

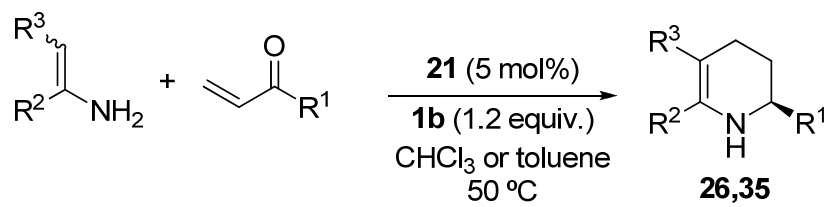<smiles>CCCOc1cc2ccccc2c(-c2c(OP(=O)(O)O)c(Br)cc3ccccc23)c1OP(=O)(O)OC</smiles>

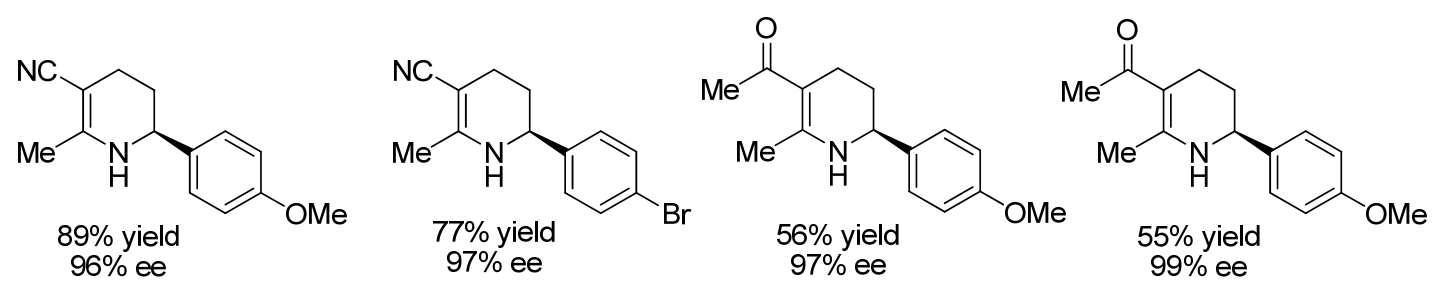<smiles>CC(=O)C1=C(C)N[C@H](c2ccc(Br)cc2)CC1</smiles><smiles>CC(=O)C1=C(C)N[C@H](c2ccc(F)cc2F)CC1</smiles><smiles>COc1ccc(C2CCC(C(C)=O)=C(C)N2)cc1</smiles><smiles>COc1ccc(C2CCC3=C(CCCC3=O)N2)cc1</smiles><smiles>O=C1CCCC2=C1CCC(c1ccccc1)N2</smiles><smiles>Cc1ccc([C@@H]2CCC3=C(CCCC3=O)N2)cc1</smiles><smiles>O=C1CCCC2=C1CC[C@H](c1ccc(Br)cc1)N2</smiles><smiles>O=C1CCCC2=C1CC[C@@H](c1ccc3c(c1)OCO3)N2</smiles><smiles>O=C1CCCC2=C1CC[C@H](c1ccc(C(F)(F)F)cc1)N2</smiles><smiles>O=C1CCCC2=C1CCC(c1ccc(F)cc1F)N2</smiles><smiles>Cc1ccc([C@@H]2CCC3=C(CCCC3=O)N2)s1</smiles><smiles>CCCCC[C@@H]1CCC2=C(CCCC2=O)N1</smiles>

Scheme 3.11 Synthesis of tetrahydropyridines 26 and azadecalinones 35 . 
An interesting mechanism was suggested by the authors to explain the final products obtained through this methodology, where the chiral Brønsted acid catalyst 21 would participate in the six reaction steps proposed (Scheme 3.12).
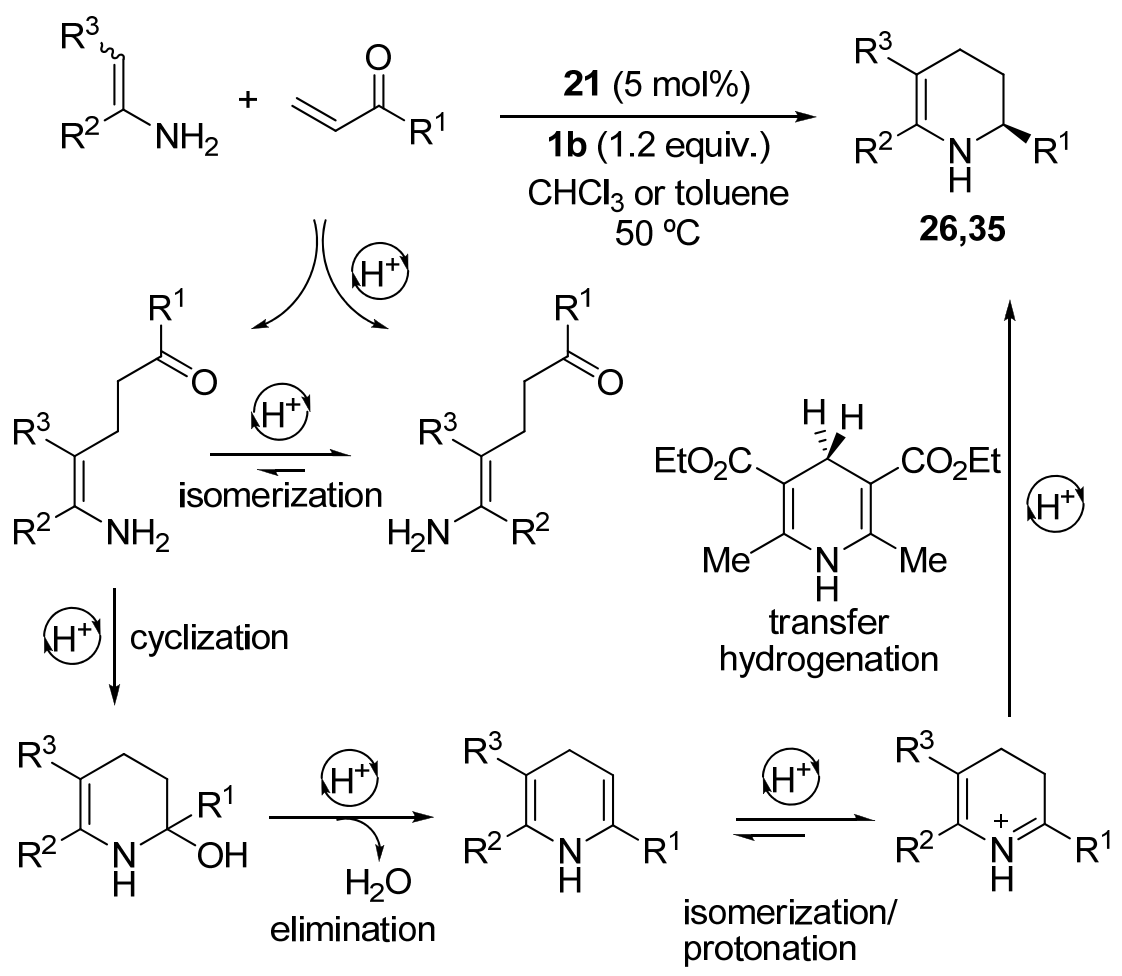

Scheme 3.12 Proposed mechanism for the cascade reaction.

Other interesting examples of catalytic transfer hydrogenation have been also described for the transformation of quinoxaline and quinoxalinones into the corresponding 2tetrahydroquinoxalines 36 (Figure 3.4) and 3-dihydroquinoxalinones 37 (Figure 3.5),[42] which structural core exhibits remarkable biological properties.[43] 
<smiles>c1ccc([C@@H]2CNc3ccccc3N2)cc1</smiles>
$98 \%$ yield 95:5 e.r.<smiles>Clc1ccc2c(c1)N[C@H](c1ccccc1)CN2</smiles>
$89 \%$ yield 92:8 e.r.<smiles>Brc1ccc2c(c1)NC[C@@H](c1ccccc1)N2</smiles>

$95 \%$ yield 96:4 e.r.<smiles>Brc1ccc2c(c1)N[C@@H](c1ccccc1)CN2</smiles>

$94 \%$ yield 91:9 e.r.<smiles>Clc1ccc2c(c1)NC[C@@H](c1ccccc1)N2</smiles>

$87 \%$ yield 97:3 e.r.<smiles></smiles>

$82 \%$ yield 95:5 e.r.<smiles>Brc1cccc(C2CNc3ccccc3N2)c1</smiles><smiles>Clc1cc2c(cc1Cl)N[C@H](c1ccccc1)CN2</smiles>

93\% yield 99:1 e.r.<smiles>Cc1ccc([C@@H]2CNc3ccccc3N2)cc1</smiles>

$98 \%$ yield 97:3 e.r.

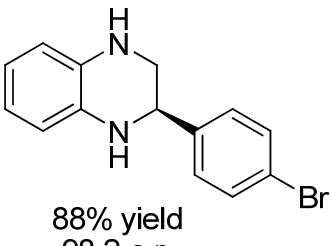
98:2 e.r.<smiles>COc1ccc(C2CNc3ccccc3N2)cc1</smiles>
97:3 e.r.<smiles>c1coc(C2CNc3ccccc3N2)c1</smiles>

93\% yield 91:9 e.r.<smiles>Clc1ccc([C@@H]2CNc3ccccc3N2)cc1Cl</smiles><smiles>c1csc([C@@H]2CNc3ccccc3N2)c1</smiles>

$97 \%$ yield 90:10 e.r.

Figure 3.4 Scope of the reaction for the generation of 2-tetrahydroquinoxalines 36 .<smiles>O=C1Nc2ccccc2N[C@H]1c1ccccc1</smiles>

$42 \%$ yield 99:1 e.r.<smiles>O=C1Nc2ccccc2N[C@H]1c1ccc2ccccc2c1</smiles>

$60 \%$ yield 99:1 e.r.<smiles>Cc1cc(C)cc([C@H]2Nc3ccccc3NC2=O)c1</smiles><smiles>CC(C)(C)c1ccc([C@H]2Nc3ccccc3NC2=O)cc1</smiles>

99:1 e.r.<smiles>COc1ccc([C@@H]2Nc3ccccc3NC2=O)cc1</smiles>

99:1 e.r.

Figure 3.5 Scope of the reaction for the generation of 3-dihydroquinoxalinones 37 .

Interestingly, Shi, Tu and co-workers developed the tandem version of the abovementioned protocol comprising a cyclization/transfer hydrogenation strategy leading to enantioenriched 
tetrahydroquinoxalines $\mathbf{3 6}$ and dihydroquinoxalinones $\mathbf{3 7}$ from readily accessible materials with excellent results in terms of reactivity and enantioselectivity (Scheme 3.13).[44]

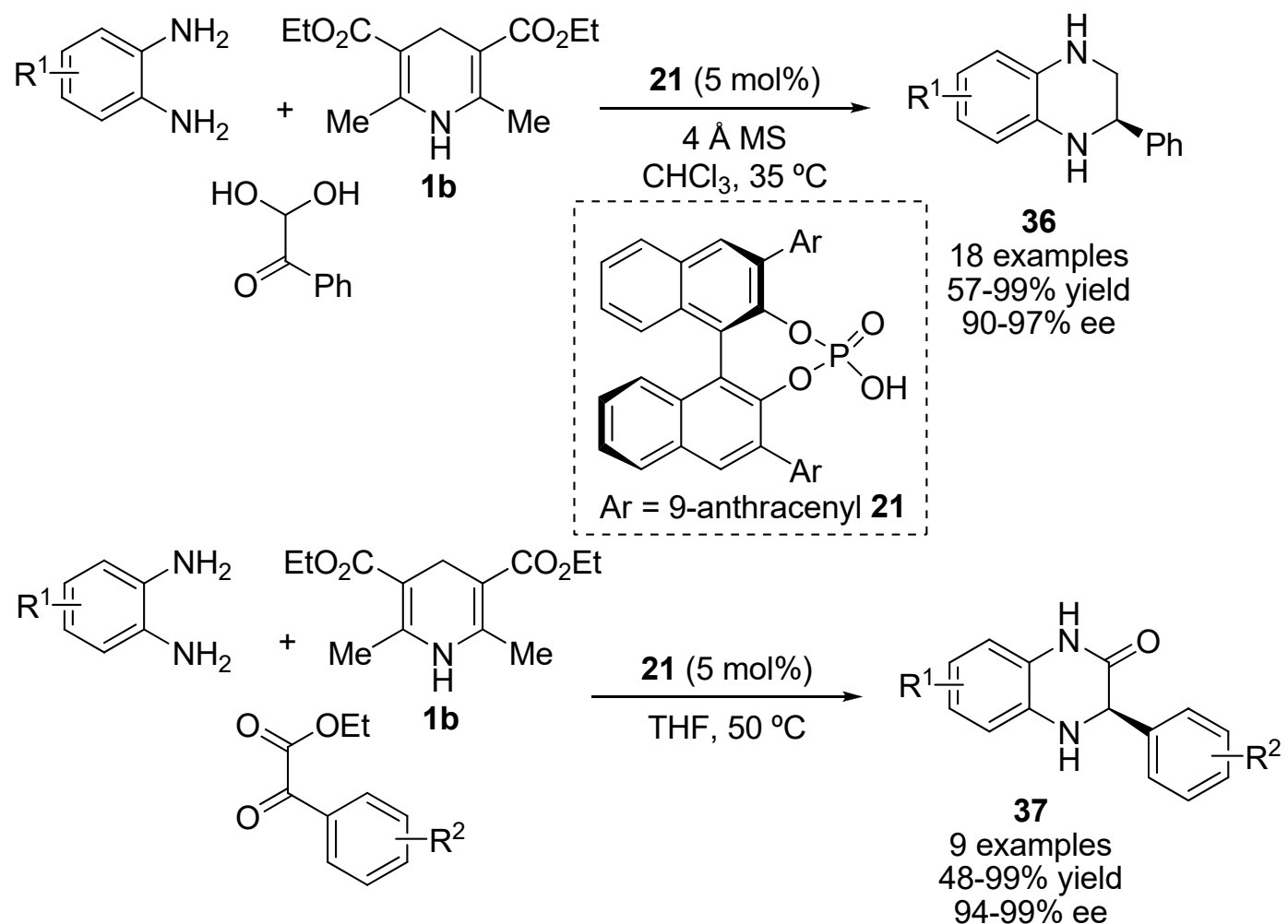

Scheme 3.13 Tandem approach for the preparation of $\mathbf{3 6}$ and $\mathbf{3 7}$.

In order to explain the stereochemical outcome observed in this process, the authors proposed a plausible reaction pathway and transition state on the basis of their experimental results and previously reported calculations on transfer hydrogenation of imines[18] (Scheme 3.14). In this mechanism, the phosphoric acid catalyst $\mathbf{2 1}$ would act in a bifunctional mode and the attack of the hydride in the TS justifies the absolute $(R)$-configuration observed in final products $\mathbf{3 6}$ and 37.

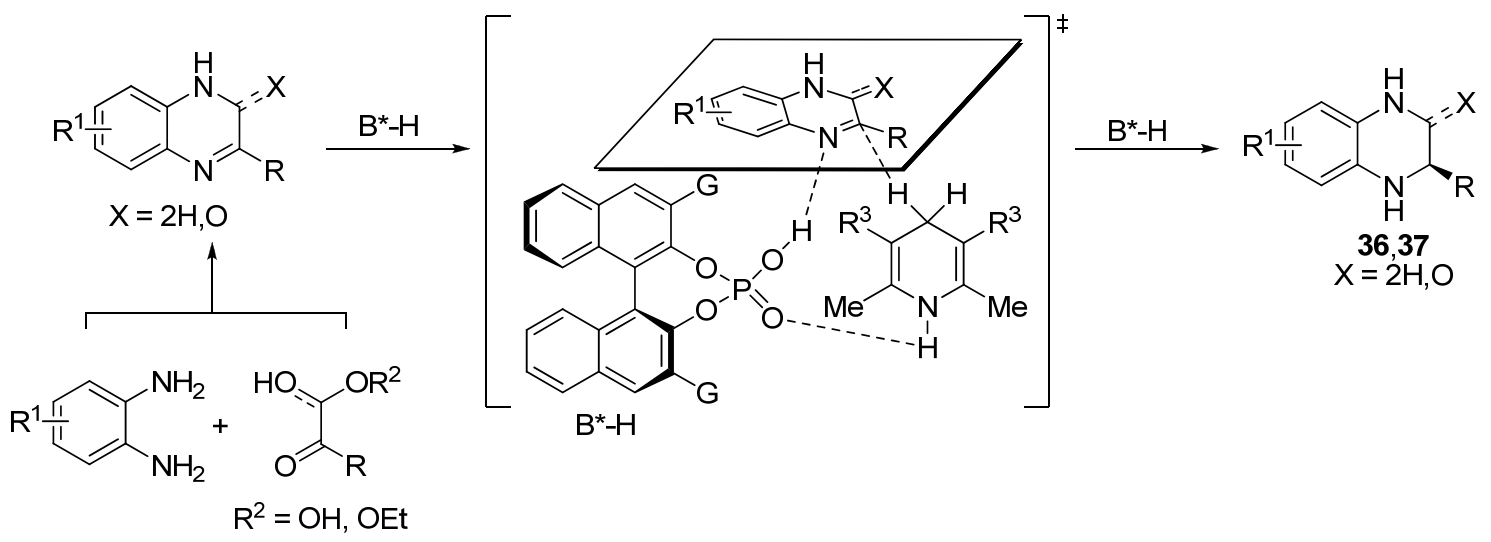


Scheme 3.14 Plausible reaction pathway and transition state.

Rueping and co-workers have recently developed a highly enantioselective synthesis of differently substituted tetrahydroquinolines $\mathbf{4 0}$ via a first photocyclization of substituted 2aminochalcones $\mathbf{3 8}$ and subsequent Brønsted acid catalyzed asymmetric reduction of the in situ generated quinoline 39, to give final products in moderate to high yields and with excellent enantioselectivities (Scheme 3.15).[45]

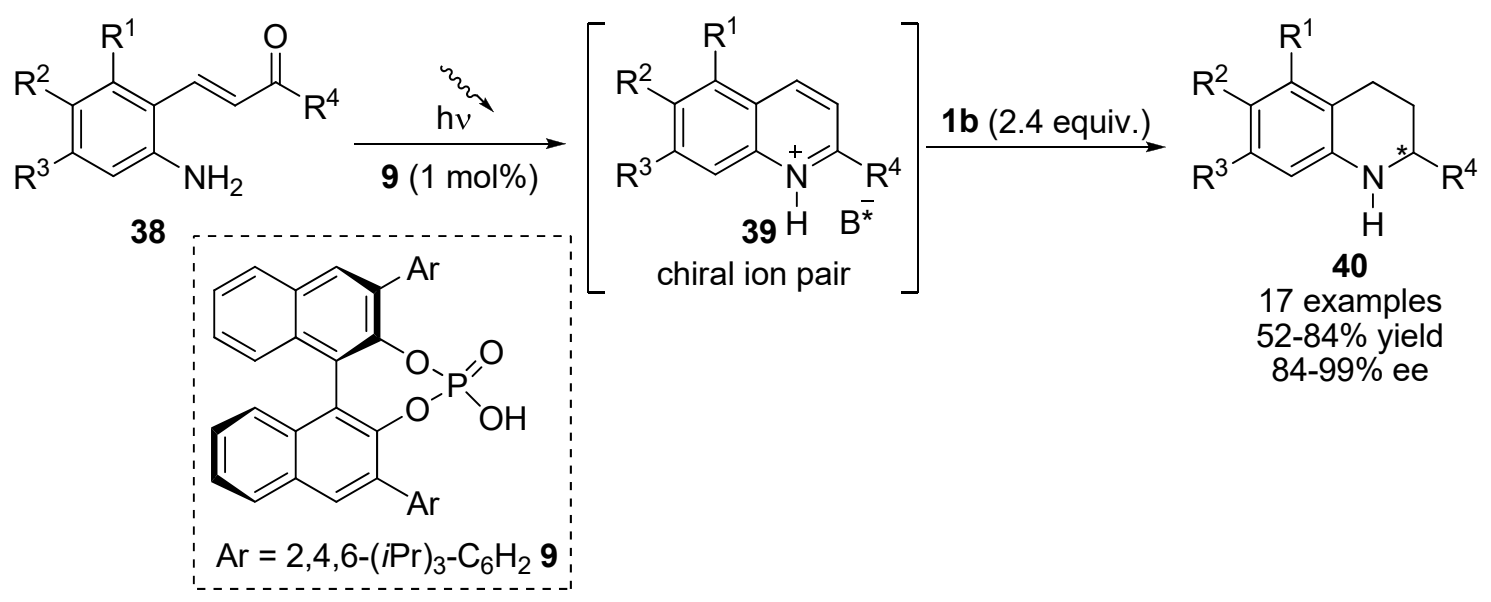

Scheme 3.15 Photocyclization-asymmetric reduction of 38 .

The same research group applied the above methodology for the synthesis of valuable $4 \mathrm{H}$ chromenes $\mathbf{4 3}$ in good yields and with excellent enantioselectivities. The approach consists of a dual light and Brønsted acid mediated isomerization-cyclization reaction starting from enones 41 to yield $2 H$-chromen-2-ol intermediates A. The subsequent Brønsted acid catalyzed elimination of water leads to an unprecedented intermediary chiral ion pair between a benzopyrylium ion and a chiral phosphate anion B. The following transfer hydrogenation exclusively occurs in the 4-position, providing the desired enantioenriched $4 H$-chromenes $\mathbf{4 3}$ (Scheme 3.16).[46] 
<smiles>[R]c1ccc(O)c(/C([Al])=C/C(=O)[Al])c1</smiles>

41<smiles>[Y]c1ccccc1C</smiles><smiles>[R]c1ccc2c(c1)C([Al])=CC(O)([Al])O2</smiles>

A<smiles>[R]c1ccc2c(c1)C([Y17])([NH3+])C=C([Al])O2</smiles>

43

15 examples $50-98 \%$ yield $80-94 \%$ ee

$$
\mathrm{Nu}=\left[\mathrm{H}^{-}\right]\lceil 1 \mathrm{~d}
$$

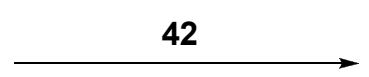

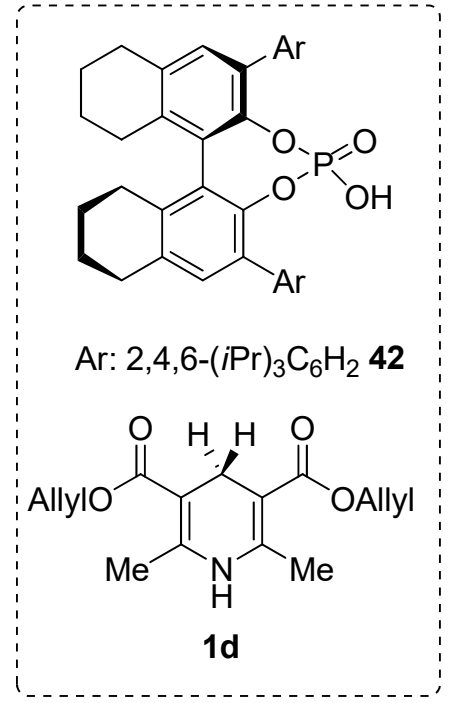

Scheme 3.16 First asymmetric Brønsted acid catalyzed hydrogenation of benzopyrylium ion $\mathbf{B}$.

Recently, a pioneering organocatalytic asymmetric reduction strategy for the synthesis of chiral 1,1-diarylethanes $\mathbf{4 6}$ with high efficiency and enantioselectivity was reported by Zhu, Lin, Sun and co-workers (Scheme 3.17).[47]<smiles>C=C(Br)c1cc[R]#cc1O</smiles>

44

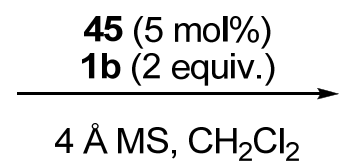

r.t.<smiles></smiles><smiles>[R]Oc1cc[R]cc1C(C)([15N])[Al]</smiles>

$\mathrm{R}^{\prime}=\mathrm{H}$ or $\mathrm{TMS}$

46

14 examples yield $64-98 \%$

ee $75-99 \%$

Scheme 3.17 Enantioselective synthesis of 1,1-diarylethanes 46 .

A plausible reaction mechanism is hypothesized by the authors. The electron-rich styrene substrate 44 would be protonated by phosphoric acid catalysts 45 to generate the tertiary carbocation intermediate $\mathbf{A}$. The neutral resonance structure $\mathbf{B}$, activated by $\mathrm{B}^{*}-\mathrm{H}$ would receive the subsequent hydride addition giving the observed products 46 and regenerating the chiral acid catalyst 45 (Scheme 3.18). 
<smiles>[R]#CC(=C)c1ccccc1O</smiles>

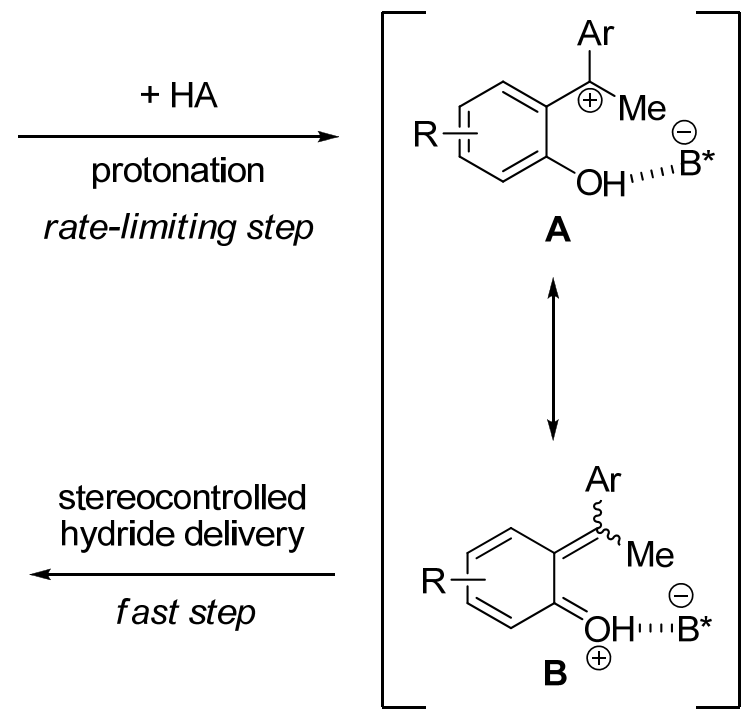

Scheme 3.18 Plausible reaction mechanism.

To support the reaction mechanism and to better understand the role of each species, the authors performed B3LYP-D3 density functional theory (DFT) calculations. Interestingly, the method was applied to a broad spectrum of substrates, and a lead compound with impressive inhibitory activity against a number of cancer cell lines was also identified.

\subsubsection{Aminocatalysis promoted transfer hydrogenation}

Other great area of research in organocatalysis that has experienced an incredible growth has been the aminocatalysis. Proof of this progress is the huge number of works focused on this field.[48] Among all of them, pivotal contributions related with transfer hydrogenations have been also developed in this area. Although less explored than the phosphoric acid catalyzed examples, these pivotal works will be recovered in the next examples.

In 2004, List and co-workers[49] pioneered only one chiral example of a novel iminium catalytic conjugate reduction of $\alpha, \beta$-unsaturated aldehyde $\mathbf{4 7 a}$ (Scheme 3.19, a). In 2005, and independently, List's (Scheme 3.19, b)[50] and MacMillan's groups (Scheme 3.19, c)[51,52] reported two more extensive protocols for the enantioselective conjugate reduction of $\alpha, \beta$ unsaturated aldehydes $\mathbf{4 7}$ and $\mathbf{5 1}$ using chiral imidazolinone catalysts $\mathbf{5 0}$ and $\mathbf{5 2}$. 
<smiles>CC(C)(C)C1NC(Cc2ccc(OCc3ccccc3)cc2)C(=O)N1C(C)(C)C</smiles><smiles>CC([Al])=CCO</smiles>

47<smiles>[R]C([R])=CC=O</smiles>

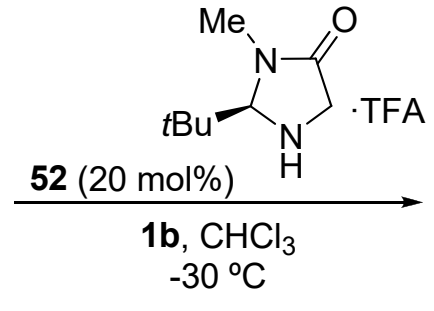<smiles>CC(CC=O)c1ccc([N+](=O)[O-])cc1</smiles>

(a)<smiles>CC([Al])CC=O</smiles>

8 examples

$70-90 \%$ yield<smiles>[R][R]CCC=O</smiles>
53

9 examples $74-95 \%$ yield $90-97 \%$ ee

Scheme 3.19 Pioneering examples of conjugated reduction of $\alpha, \beta$-unsaturated aldehydes.

List's group proposed a reasonable mechanism to explain the observed absolute configuration in their final products 49 . The process would firstly proceed by formation of iminium ion $\mathbf{5 4}$, which could isomerize quickly via dienamine 55 (Scheme 3.20). The authors assume that the rate determining step would be the hydride transfer from 1a to iminium $(E)-\mathbf{5 4}$ via the transition state $\mathbf{A}$, which would occur faster than $(Z)-54[\mathrm{k}(\mathrm{E})>\mathrm{k}(\mathrm{Z})]$ and, as a result, the enantiomer $R$ would be predominantly formed (Scheme 3.20).[50] 

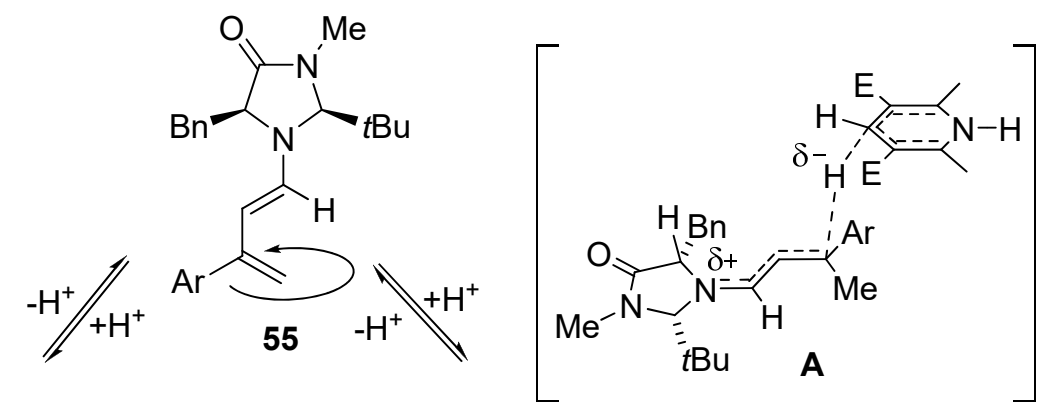

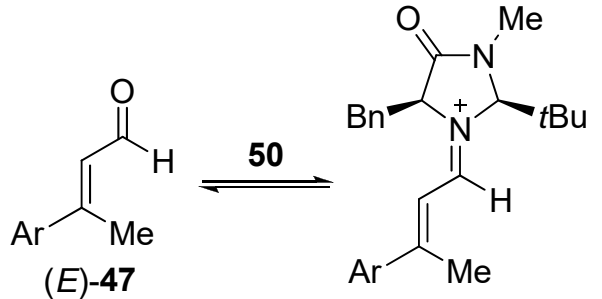

$(E)-54$

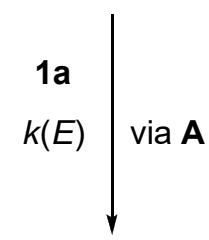

$(R)-49$

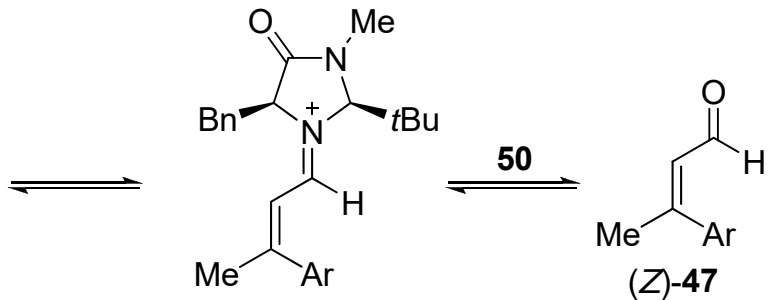

$(Z)-54$

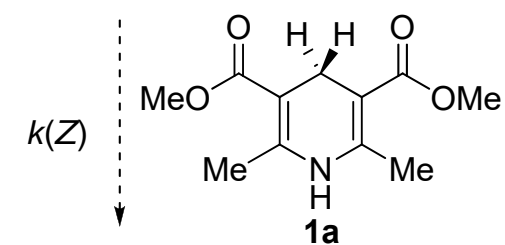

$(S)-49$

Scheme 3.20 Mechanistic hypothesis of the organocatalytic asymmetric transfer hydrogenation. Later, the first enantioselective organocatalytic transfer hydrogenation involving cyclic enones was reported by MacMillan and co-workers following an operationally simple and rapid protocol that allowed access to chiral $\beta$-substituted cycloalkenones $\mathbf{5 8}$ with very good yields and high enantioselectivities (Scheme 3.21).[53,54] 


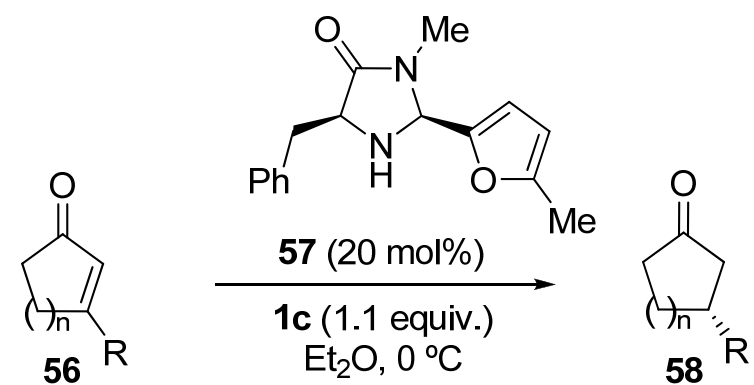

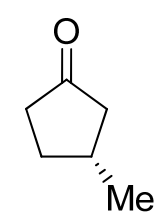

$9 \mathrm{~h}$ $72 \%$ yield $95 \%$ ee<smiles>O=C1CC[C@H](c2ccccc2)C1</smiles>

$9 \mathrm{~h}$ $73 \%$ yield 91\% ee<smiles>O=C1CCC[C@@H](Br)C1</smiles>

$25 \mathrm{~h}$

$82 \%$ yield $90 \%$ ee

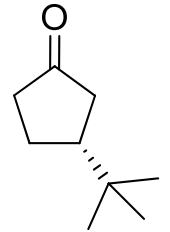

$6 \mathrm{~h}$ $81 \%$ yield $96 \%$ ee<smiles>O=C1CCCC1</smiles>

$8 \mathrm{~h}$ $85 \%$ yield $96 \%$ ee<smiles>C[C@H]1CC(=O)CC(C)(C)C1</smiles>

$40 \mathrm{~h}$ $66 \%$ yield $98 \%$ ee<smiles>O=C1CC[C@@H](Cc2ccccc2)C1</smiles>

$11 \mathrm{~h}$ $78 \%$ yield $90 \%$ ee<smiles>CC(=O)[C]1CCC(=O)C1</smiles>

$1 \mathrm{~h}$ $78 \%$ yield 91\% ee<smiles>[R16]CC1CCCCC1</smiles>
$71 \%$ yield $88 \%$ ee<smiles>O=C1CC[C@@H](Br)C1</smiles>

$13 \mathrm{~h}$ $89 \%$ yield $91 \%$ ee<smiles>COC(=O)[C]1CCC(=O)C1</smiles>

$1 \mathrm{~h}$ $83 \%$ yield $90 \%$ ee<smiles>O=C1CCCC[C@@H](Br)C1</smiles>

$9 \mathrm{~h}$

$70 \%$ yield

$92 \%$ ee

Scheme 3.21 Scope of the organocatalytic enone hydrogenation.

In order to explain the sense of the asymmetric induction observed in final products $\mathbf{5 8}$, the authors proposed a plausible attack of the hydride based on the selective engagement of the Hantzsch ester reductant 1c over the $\mathrm{Si}$ face of the cis-iminium isomer $\mathbf{A}$ (Scheme 3.22). 


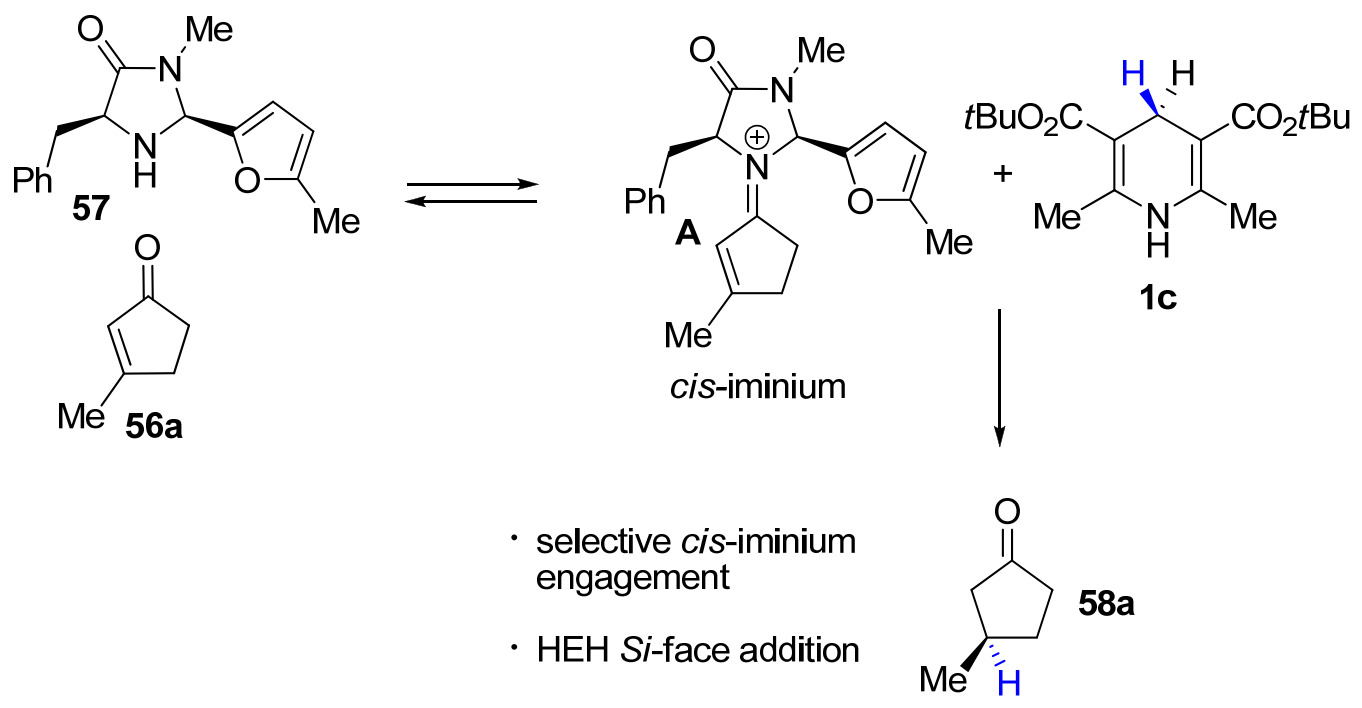

Scheme 3.22 Enantioselective hydride addition mechanism.

Interestingly, in this work the authors compared the efficiency of esters $\mathbf{1 b}, \mathbf{1 c}$ and $\mathbf{1 d}$, in order to observe a possible structural effect of them over the enantioselectivity and the reactivity of this process. In fact, a significant impact on both aspects was found with a plausible correlation on the size of the ester functionality at the 3,5-dihydropyridine site (1b: Et, 96\% conversion, 74\% ee; $1 \mathrm{~d}$ : $i$-Pr, $78 \%$ conversion, $78 \%$ ee and $1 \mathrm{c}: t$ - $\mathrm{Bu}, 86 \%$ conversion, $91 \%$ ee). The enantiocontrol results were explained in terms of electronic factors between the hydrogen substituents at the 4-position and the nitrogen lone-pair. The boat conformation found for 1c would facilitate the overlap between one $\mathrm{H}$ (4-position) in an axial orientation with the nitrogen lone-pair in the ground state. In contrast, $\mathbf{1 b}$ ring is found in a planarized form wherein poor $\pi$ orbital overlap between the analogous $\mathrm{C}-\mathrm{H}$ bond and nitrogen renders a less reactive hydride reagent. This hypothesis is consistent with not only an increase in enantiocontrol when using the more bulky tert-butyl Hantzsch ester $\mathbf{1 c}$ but also improved reaction rate and efficiency.[5a,53] Bringing together the concept of aminocatalysis and the activation mode of chiral phosphoric acids, List and co-workers introduced the concept of asymmetric counter anion directed catalysis (ACDC) applying this idea to the asymmetric reduction of enals 47 (Scheme 3.23).[55] The catalytic species is formed by an achiral ammonium ion $\mathbf{6 0}$ and a chiral phosphate anion $\mathbf{5 9}$ derived from 3,3'-bis(2,4,6-triisopropylphenyl)-1,1'-binaphthyl-2,2'-diyl hydrogen phosphate 9 (TRIP). 


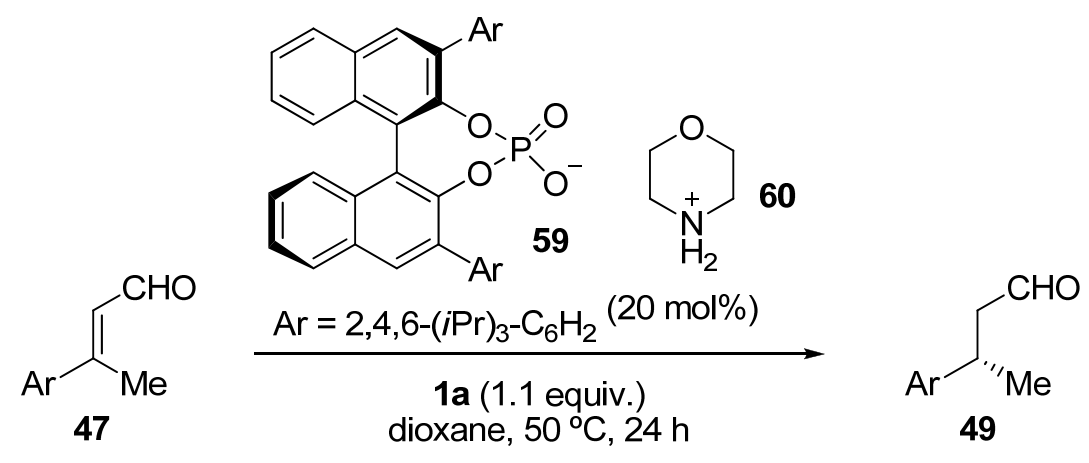<smiles>Cc1ccc(C(C)CC=O)cc1</smiles><smiles>C[C@@H](CC=O)c1ccc2ccccc2c1</smiles>

Scheme 3.23 ACDC approach applied to the reduction of enals 47 .

All reduced $\beta, \beta$-disubstituted enals 49 were obtained in good yields (up to 90\%) and excellent enantioselectivities (up to $99 \%$ ee). Moreover, the methodology was applied to the interesting reduction of citral 61 into the $(R)$-citronellal 62 and to the asymmetric reduction of farnesal 63 , in all cases with excellent enantioselectivies and high yields (Scheme 3.24).

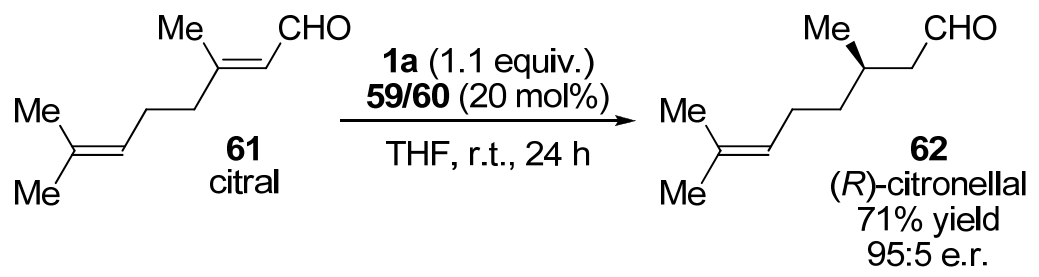<smiles>CC(C)=CCCC(C)=CCCC(C)=CC=O</smiles>

63

farnesal

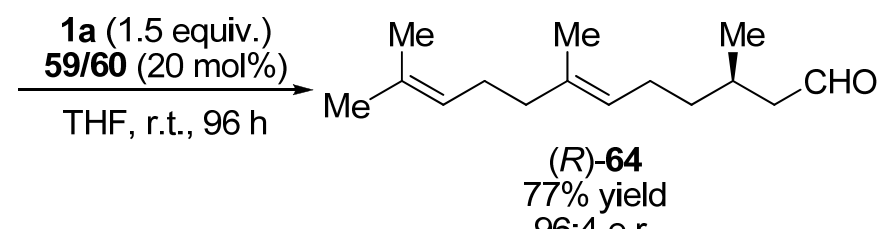

96:4 e.r.

Scheme 3.24 Catalytic asymmetric transfer hydrogenation of citral 61 and farnesal 63 . 
Remarkably, the same final enantiomer was obtained in the products even starting from $\mathrm{Z}$ enals, what is in agreement with a stereoconvergent catalytic system and a rapid $\mathrm{E}-\mathrm{Z}$ equilibration, as detected by NMR spectroscopic studies. The mechanism is believed to occur via an iminium ion intermediate since salts of tertiary amines seem to be ineffective.

An extension of this work was reported by the same research group for the asymmetric conjugate reduction of $\alpha, \beta$-unsaturated ketones 65 , affording final reduced products 67 with high yields and good to excellent enantioselectivities (Scheme 3.25).[56]<smiles>[R]C(=O)C=C([R])[R]</smiles>

65

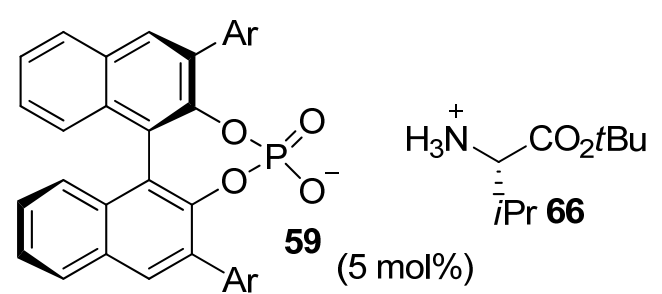

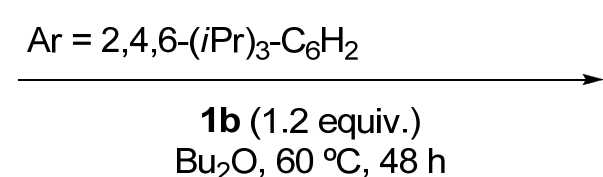
$\mathrm{Bu}_{2} \mathrm{O}, 60^{\circ} \mathrm{C}, 48 \mathrm{~h}$<smiles>[R]C(=O)CC([R])[R]</smiles>

67

12 examples $68-99 \%$ yield $70-98 \%$ ee

Scheme 3.25 Asymmetric reduction of ketones 65 .

More recently, Lear and co-workers applied this new concept as a key synthetic step in the high yielding route leading to the (-)-platensimycin core.[57,58]

\subsubsection{Thiourea-catalyzed transfer hydrogenation}

Another big family of organocatalysts that has been successfully used in hydrogen transfer, although less explored, is the chiral thiourea organocatalysts. $[59,60]$ In this context, List and coworkers reported the first example of conjugate reduction of nitroolefins $\mathbf{6 8}$ mediated by thiourea organocatalyst 69 (Scheme 3.26).[61,62] 


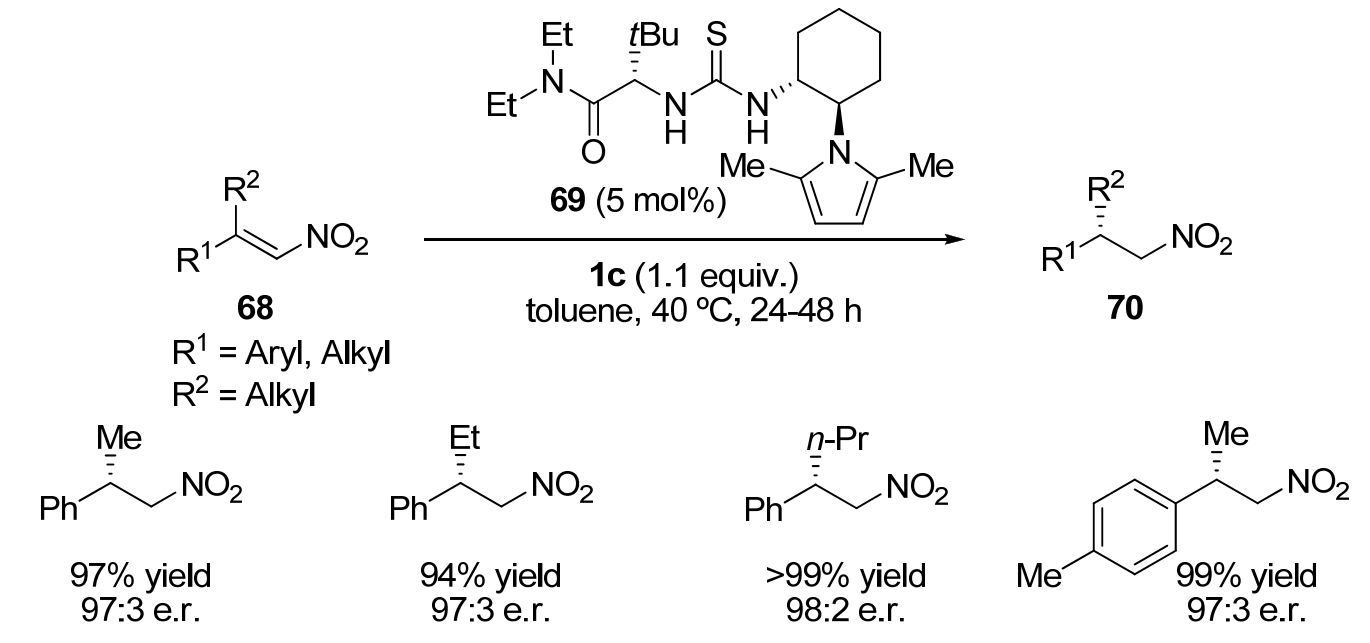<smiles>CC(C[N+](=O)[O-])c1ccc(C#N)cc1</smiles><smiles>CC(C[N+](=O)[O-])c1ccc(F)cc1O[AsH3]</smiles><smiles>CC(C[N+](=O)[O-])c1ccc(Cl)cc1[O-]</smiles><smiles>CC(C[N+](=O)[O-])c1ccc(Cl)cc1[O+]</smiles><smiles>CC(C[N+](=O)[O-])c1cc2ccccc2cc1O[Mg]</smiles><smiles>CC(C[N+](=O)[O-])c1ccco1</smiles><smiles>CC(C)(C)C(C)(C)C[N+](=O)[O-]</smiles><smiles>CCC(C)C[N+](=O)[O-]</smiles>

Scheme 3.26 Thiourea promoted asymmetric transfer hydrogenation.

As disclosed, the process was suitable for a broad substrate scope, leading to final products $\mathbf{7 0}$ with high yields and enantioselectivities for diverse $\beta$-alkylsubstituted nitrostyrenes $\mathbf{6 8}$.

The reaction could proceed via a hydrogen-bonding interaction between the $\mathrm{NH}$ of the thiourea moiety and the nitro group and further enantioselective attack of the hydride from the Hantzsch ester $\mathbf{1 c}$.

An extension of this work was reported by the same research group using $\beta$-nitroacrylates 71 and the same thiourea organocatalyst $\mathbf{6 9}$ with the main aim of preparing the corresponding saturated $\beta$-nitroesters 72 in high yields and enantioselectivities, which can be easily converted into $\beta^{2}$-amino acids via hydrogenation (Scheme 3.27). [63,64] 


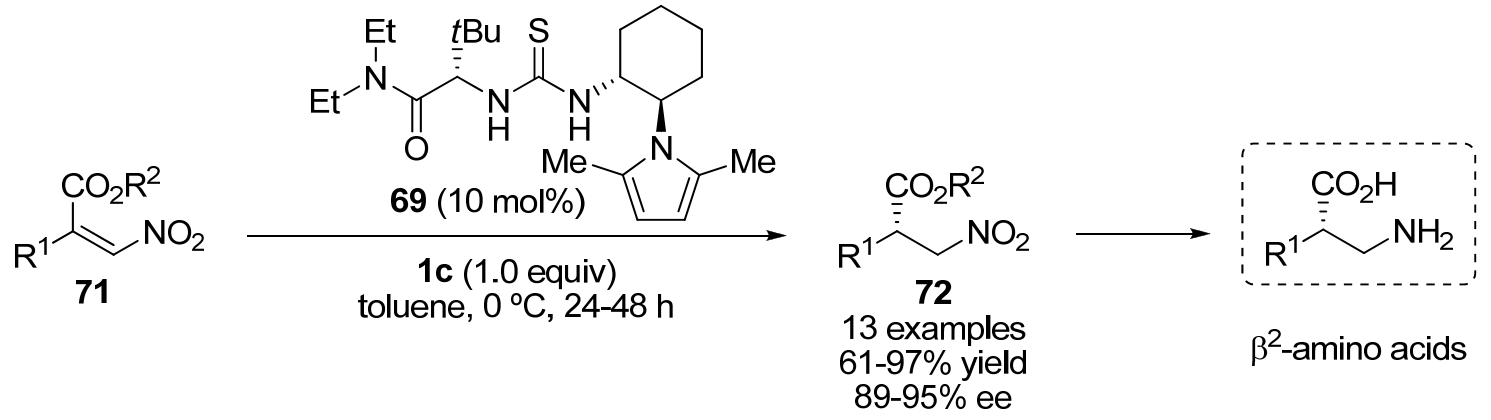

Scheme 3.27 Asymmetric reduction of $\beta$-nitroacrylates.

The same approach was used by Benaglia's group for the enantioselective organocatalytic reduction of $\beta$-trifluoromethyl nitroalkenes 73, with the aim of achieving chiral $\beta$ trifluoromethyl amines 75 (Scheme 3.28).[65] The authors also performed the organocatalyzed reduction of $\alpha$-substituted- $\beta$-trifluoromethyl nitroalkenes, although with poorer results. The stereochemical result of the reaction and the behavior of thiourea catalyst $\mathbf{7 4}$ were discussed based on computational studies and DFT transition-state analysis.<smiles>[R]/C(=C\[N+](=O)[O-])C(F)(F)F</smiles><smiles>Cc1ccc(C(C[N+](=O)[O-])C(F)(F)F)cc1</smiles>

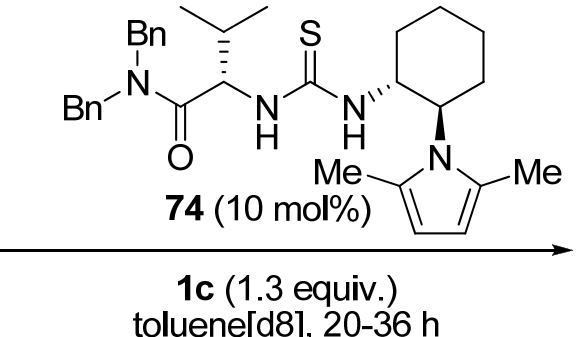

toluene[d8], 20-36 h<smiles>[R]C(C[18O])C(F)(F)F</smiles><smiles>O=[N+]([O-])CC(c1ccc(F)cc1)C(F)(F)F</smiles>

$90 \%$ ee<smiles>Cc1cccc(C(C[N+](=O)[O-])C(F)(F)F)c1</smiles><smiles>O=[N+]([O-])CC(c1ccc(Cl)cc1)C(C(F)(F)F)C(F)(F)F</smiles><smiles>O=[N+]([O-])CC(Cc1ccccc1)C(F)(F)F</smiles>

$89 \%$ yield $90 \%$ ee<smiles>O=[N+]([O-])CC(CC1CCCCC1)C(F)(F)F</smiles>

$80 \%$ yield $97 \%$ ee<smiles>C[C@H](C[N+](=O)[O-])C(F)(F)F</smiles>

$75 \%$ yield

$93 \%$ ee

Scheme 3.28 Organocatalyzed reduction of fluorinated nitroolefins $\mathbf{7 3}$. 
Simultaneously, although independently, Bernardi, Fochi and co-workers developed an extraordinary additional example of highly enantioselective transfer hydrogenation using $\beta$ trifluoromethyl nitroalkenes to give easy access to optically active $\beta$-trifluoromethyl amines with excellent results.[66]

\subsection{Trichlorosilane-mediated stereoselective reduction of $\mathrm{C}=\mathrm{X}$ bonds}

In the last decade, great progress has been made in the development of highly enantioselective Lewis basic organocatalysts for the reactions of trichlorosilyl derivatives as the reducing agents. 2 is activated by the base moiety of the catalyst to generate an hexacoordinate hydridosilicate.[67] Here is reported the successful application on the enantioselective reduction of prochiral ketimines, ketones and $\mathrm{C}=\mathrm{C}$ bond using trichlorosilane $\mathbf{2}$ as an effective hydride source.

\subsubsection{Reduction of ketimines}

\subsubsection{1 $\mathrm{N}$-Formylpyrrolidine derivatives}

In a pioneering work, Matsumura and co-workers presented a new finding where trichlorosilane 2 activated with $N$-formylpyrrolidine derivatives 77 was an effective catalyst for the reduction of imines 76. Reducing agent 2 showed much higher selectivity towards the imino group rather than the carbonyl group, because the carbonyl moiety in the catalysts was not reactive against the reduction (Scheme 3.29).[68] Later, Tsogoeva's group demonstrated the use of pyrrolidine 78 as suitable catalyst for ketimines reduction, although only for one example and using HMPA as additive.[69] More recently, Lewis base $\mathbf{7 9}$ was successfully employed for the hydrosilylation of $\alpha$-imino esters as direct precursors of $\alpha$-amino acids.[70,71] 


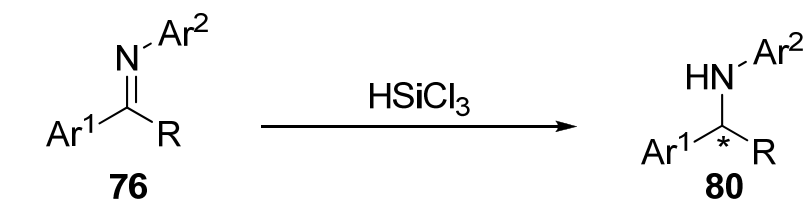

$$
\mathrm{R}=\mathrm{Me}, \mathrm{CO}_{2} \mathrm{Et}
$$

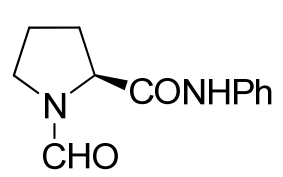

77

yield up to $99 \%$

ee up to $55 \%$

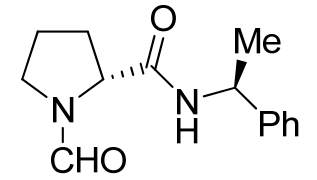

78

$75 \%$ yield $81 \%$ ee<smiles>O=C(Oc1ccccc1)O[C@H]1C[C@@H](C(O)(c2ccccc2)c2ccccc2)N(C(=O)c2ccccn2)C1</smiles>

$71-97 \%$ yield $15-93 \%$ ee

Scheme 3.29 Reduction of imines with $N$-formylpyrrolidine based catalysts.

The role of the carbonyl groups in the catalysts seemed to be responsible of the silicium activation.[72] In order to explain the sense of the enantioselection in final products Matsumura's group suggested that the reduction predominantly proceeded through a transition state $\mathbf{A}$ rather than the most hindered transition state $\mathbf{B}$, justifying the major enantiomer observed (Figure 3.6). This mechanistic proposal was an early hypothesis, which was later modified by other authors on the base of more experimental results (see below).

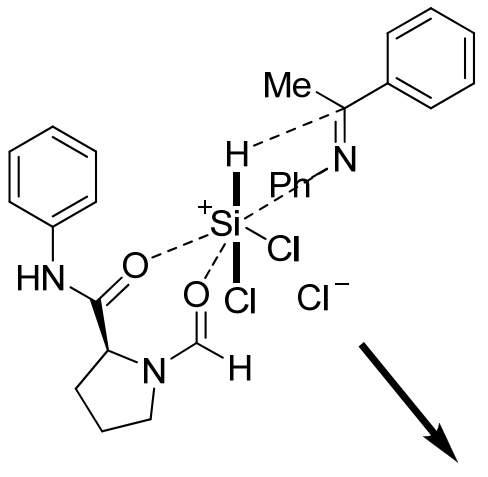

TSA

$(R)$

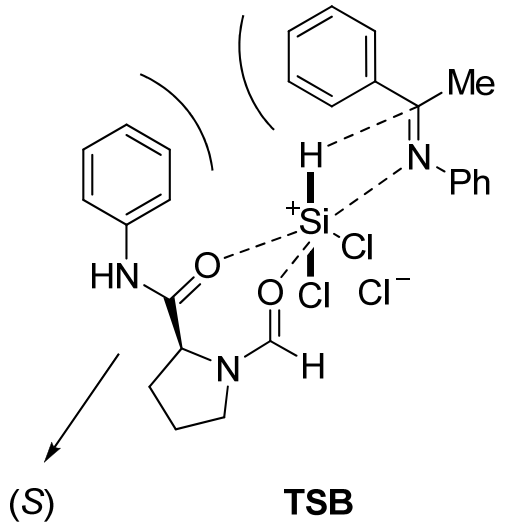

Figure 3.6 Mechanism of hydrosilylation of imines.

\subsubsection{L-Valine-derived $N$-methyl formamides}

Malkov, Kočovský and co-workers have developed different L-valine-based Lewis basic catalysts such as $\mathbf{8 1},[73,74]$ for the efficient asymmetric reduction of ketimines $\mathbf{7 6}$ with trichlorosilane 2, or catalyst 82[75] with a fluorous tag which allows an easy isolation of the product and can be used in the next cycles, while preserving high enantioselectivity of the process. Sigamide catalyst $\mathbf{8 3}[76]$ and Lewis base $\mathbf{8 4}[77]$ were employed in low amount (5 
mol\%) affording final chiral amines 80 with high enantioselectivity (Scheme 3.30).[78] Interestingly, $\mathbf{8 3}$ was used for the enantioselective preparation of vicinal $\alpha$-chloroamines and the subsequent synthesis of chiral 1,2-diaryl aziridines. In these developed approaches the same absolute enantiomer was observed in the processes.

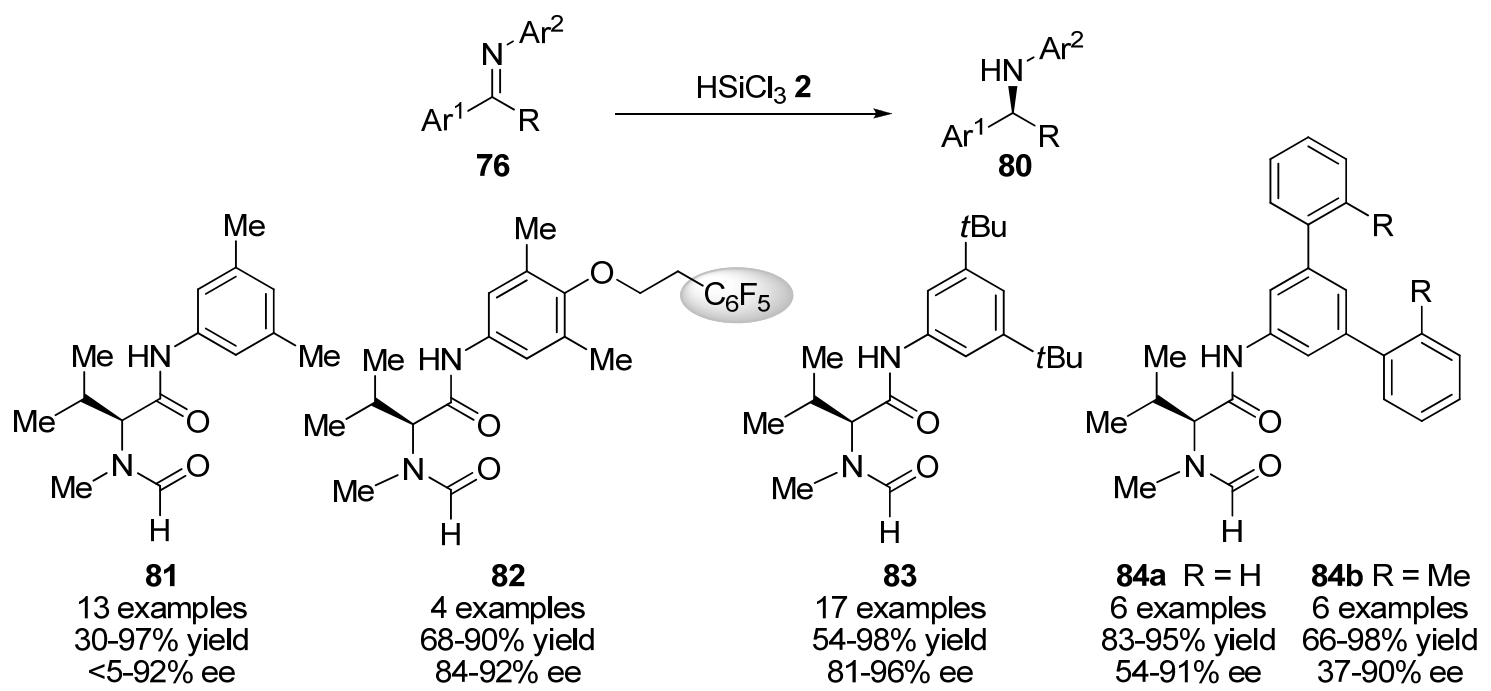

Scheme 3.30 Pioneering examples of L-valine-based Lewis basic catalysts.

From these studies, the authors suggested different important conclusions: (1) the structurereactivity studies showed that the product configuration seems to be controlled by the nature of the side chain of the catalyst scaffold, and the electronic properties of the substituents in the phenyl ring on the Lewis base. Interestingly, catalysts of the same absolute configuration may induce the formation of the opposite enantiomers of the product; (2) hydrogen bonding and arene-arene interactions between the catalyst and the imine appear to be crucial for the success determining the enantiofacial selectivity; (3) the activation of trichlorosilane seems to be in agreement with a bidentate coordination with both carbonyl groups of the amide moiety in the catalyst, as previously invoked (Figure 3.7).[73] It is remarkable that the mode of activation in this case differs from that proposed previously by Matsumura's group in Figure 3.6.[68] 


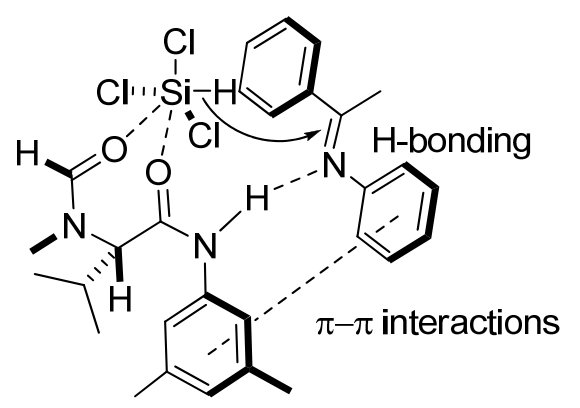

Figure 3.7 Mechanism of hydrosilylation of imines.

\subsubsection{L-Pipecolinic acid derived $N$-formamides}

Sun and co-workers developed a novel Lewis basic organocatalyst 86 (Scheme 3.31), easily synthesized from commercially available L-pipecolinic acid. 86 promoted the reduction of $\mathrm{N}$ aryl ketimines $\mathbf{8 5}$ with $\mathrm{HSiCl}_{3} \mathbf{2}$ in high yield and excellent ee values under mild conditions with an unprecedented spectrum of substrates.[79] The same group also found that L-pipecolinic acid derived $N$-formamide $\mathbf{8 7}$ was a highly effective Lewis basic organocatalyst for the same reaction.[80]

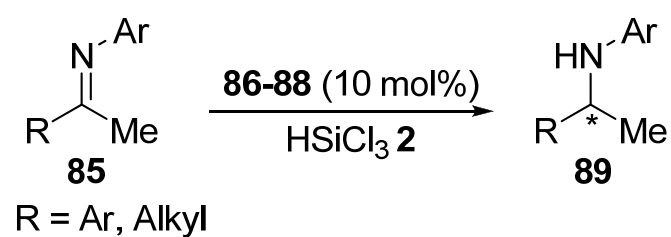<smiles>CC(=O)O[C@H](c1ccccc1)C(NC(=O)C1CCCCN1C(=O)[OH2+])c1ccccc1</smiles>

19 examples $75-98 \%$ yield $87-96 \%$ ee<smiles>COC(c1ccccc1)C(NC(=O)C1CCCCN1C(=O)Br)c1ccccc1</smiles>

12 examples $85-98 \%$ yield $83-93 \%$ ee<smiles>Cc1cc(C)cc(NC(=O)C2CCCCN2C(=O)[OH2+])c1</smiles>

Scheme 3.31 Model L-pipecolinic acid derived $N$-formamide catalysts 86-88.

On the basis of the experimental results, the methoxy group on $\mathrm{C} 2$ ' has proven to be critical for the high efficiency of catalyst $\mathbf{8 7}$ in the reduction of the imines. A hexacoordinate silicon transition structure was proposed to justify the experimental observations. In a more extended mechanistic study $N$-funtionalized pipecolinamides $\mathbf{8 8}$ were proposed as an example of efficient catalyst after several variations in the $\mathrm{C} 2$ and the $N$-protected group. $[81,82]$

\subsubsection{Piperazine Lewis base organocatalyst}


Sun and co-workers envisioned that the piperidinyl ring on the above mentioned catalysts could be replaced by a piperazinyl backbone, considering that the additional secondary amino group on the 4-position (N4) should provide a suitable site to introduce structural variations and thus accurately to modify the catalytic properties. In this context, a new catalyst $\mathbf{9 1}$ was designed (Scheme 3.32),[83] which promoted the unprecedented reduction of the relatively bulky ketimines 90, becoming a complementary structure to the existing catalytic systems. The reductions of both $N$-aryl acyclic methyl ketimines and non-methyl ketimines 90 were catalyzed for a broad spectrum of substrates affording the desired chiral amines 92 in high yields and with high ee values.

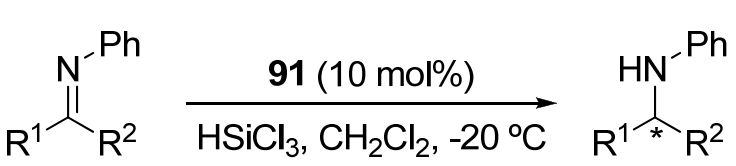
90 $\mathrm{R}^{1}=$ Aryl, $c-\mathrm{C}_{6} \mathrm{H}_{11}$ $\mathrm{R}^{2}=$ Alkyl
92 19 examples yield $63-99 \%$ ee $82-95 \%$

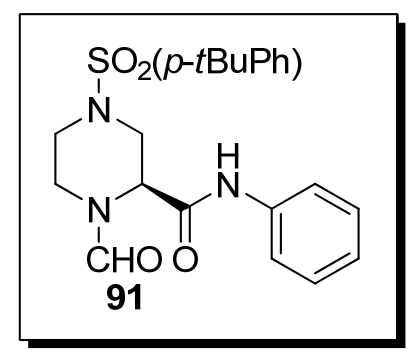<smiles>CCC(=Nc1ccc(OC)cc1)c1ccccc1/N=C(\C)c1ccccc1N=C(C)c1ccccc1OC</smiles>

Scheme 3.32 Reduction of imines using piperazine Lewis base derivative $\mathbf{9 1}$.

Unfortunately, other $N$-substituted phenyl ketimines 93a-e afforded lower ee values compared with 90. The $N$-benzyl ketimine 93e was also proven to be unsuitable substrate using 91 as catalyst. The authors found that arene sulfonyl group on N4 and the 2-carboxamide groups were crucial for the high enantioselectivity of the process and the efficiency of the catalytic system.

\subsubsection{S-Chiral sulfinamide derivatives}

Although chiral sulfur centers had been used as the chirality source on chiral auxiliaries and ligands,[84] organocatalysts incorporating chirality solely through the sulfur atom had been 
almost overlooked in the literature before the development of this subarea of research. In this context, Sun's group developed the first highly effective example of $S$-chiral sulfinamide organocatalyst $\mathbf{9 5}$ to promote the asymmetric hydrosilylation of ketimines with $\mathbf{2}$ in high yield and enantioselectivity (Scheme 3.33).[85] Having in mind the idea that two molecules of monosulfinamide catalyst could participate in the mechanism of the reaction (Figure 3.8), the same authors designed bissulfinamide 96[86] incorporating two sulfinamide units which efficiently promoted the asymmetric reduction of $N$-aryl ketimines in high yields and improved enantioselectivities (Scheme 3.33). 96 resulted to be a better catalyst than the former monosulfinamide 95.

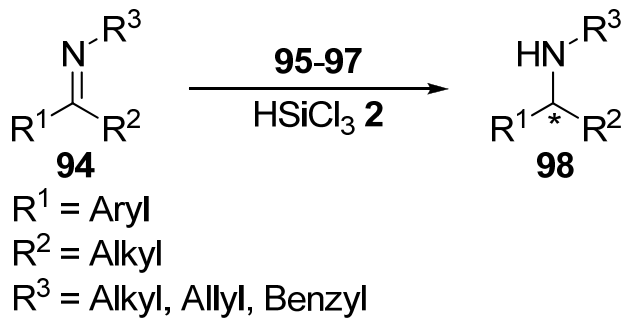<smiles>CC(C)(C)[Sn](=O)NCc1cc(F)ccc1O</smiles>

20 examples $73-98 \%$ yield $74-93 \%$ ee<smiles>CC(C)(C)S(=O)NCNS(=O)C(C)(C)C</smiles>

96 21 examples $70-95 \%$ yield $72-96 \%$ ee<smiles>Cc1cc(C)cc(NC(=O)[C@@H]2CCCN2S(=O)[O-])c1</smiles>

24 examples $54-98 \%$ yield $66-99 \%$ ee

Scheme 3.33 Example of efficient $S$-chiral sulfinamide organocatalysts 95-97.<smiles>CC(C)(C)[S@@](=O)[Si](Cl)(Cl)Cl</smiles>

Figure 3.8 Mode of action of $S$-chiral monosulfinamide organocatalysts.

The same group developed a new Lewis base organocatalyst 97 which included a $C$ - and $S$ chirality represented by a $S$-chiral sulfinamide group and a $C$-chiral $\alpha$-amino acid framework bearing Lewis basic carboxamide functionality, both for the activation of $\mathrm{HSiCl}_{3}$ 2. Excellent 
enantioselectivities and high yields for a wide range of aromatic $N$-alkyl ketimines were achived (Scheme 3.33).[87,88]

\subsubsection{Supported Lewis base organocatalysts}

With the increasing interest by developing catalysts able to be easily separated from the final product, many efforts have been devoted in the preparation of immobilized structures.[89,90] In this field, Kočovský's group has also reported interesting Lewis base supported catalysts for the efficient asymmetric hydrosilylation of ketimines with 2 . The first reported example was an $\mathrm{N}$ methylvaline derived Lewis basic formamide anchored to a polymeric support with a varying spacer 100. This protocol represented a considerable simplified procedure to isolate the catalyst from the crude of the reaction, which is not a trivial task for instance on a large scale protocol (Scheme 3.34). The polymer-supported catalyst was reused at least 5 times without any loss of activity.[91]<smiles>[R]C(C)=Nc1ccc(OC)cc1</smiles>

$$
\begin{array}{ll}
\mathrm{R}=\mathrm{Ph} & 82 \% \text { yield, } 81 \% \text { ee } \\
\mathrm{R}=2 \text {-naphthyl } & 72 \% \text { yield, } 79 \% \text { ee } \\
\mathrm{R}=4-\mathrm{CF}_{3} \mathrm{C}_{6} \mathrm{H}_{4} & 67 \% \text { yield, } 81 \% \text { ee } \\
\mathrm{R}=4-\mathrm{MeOC}_{6} \mathrm{H}_{4} & 62 \% \text { yield, } 77 \% \text { ee } \\
\mathrm{R}=2,5-\mathrm{Me}_{2}-3 \text {-furyl } 67 \% \text { yield, } 78 \% \text { ee }
\end{array}
$$

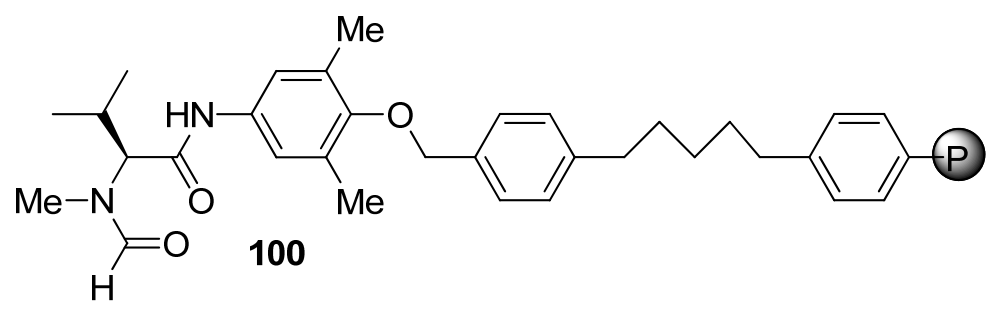

Scheme 3.34 Application of polymer-supported organocatalyst 100.

The same research group designed a soluble catalyst $\mathbf{1 0 2}$ with the main aim of avoiding the problems associated with the heterogeneous systems, and related to the common supported catalysts.[92] The main advantage of this system is the inverted solubility pattern that this catalyst exhibits, since it is soluble in non-polar solvents and insoluble in polar media (Figure 
3.9). This feature simplified the recovery (up to $99 \%$ ) and re-use of the catalyst at least five times without loss of activity, improving the results obtained with catalyst 100.[93]

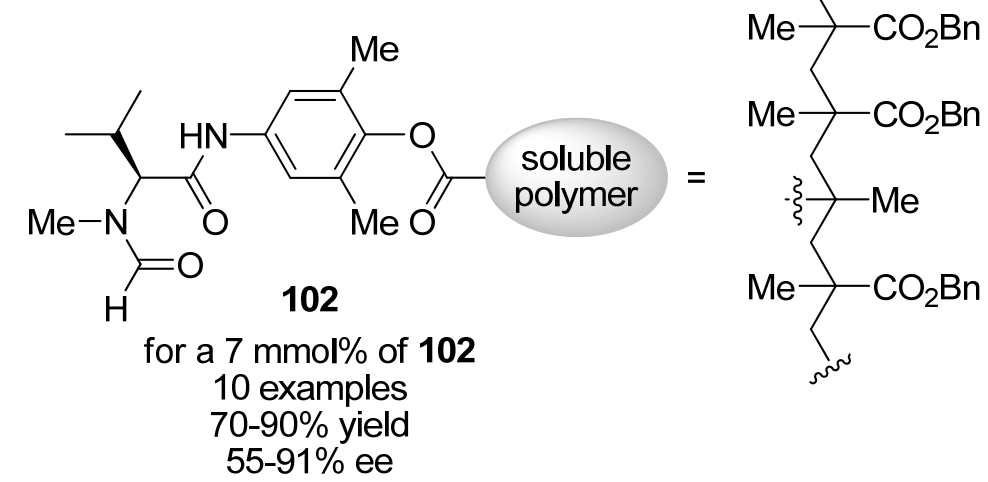

Figure 3.9 Soluble supported catalyst 102.

In order to enable the isolation procedure of the organocatalysts, Kočovský's group also reported an alternative approach using a dendron-anchored organocatalyst $\mathbf{1 0 3}$ to efficiently reduce the imines with trichlorosilane 2.[94] The isolation procedure of the catalyst from the crude was substantially simplified, since most of the catalyst $(\geq 90 \%)$ could be recovered by precipitation and centrifugation (Figure 3.10). 


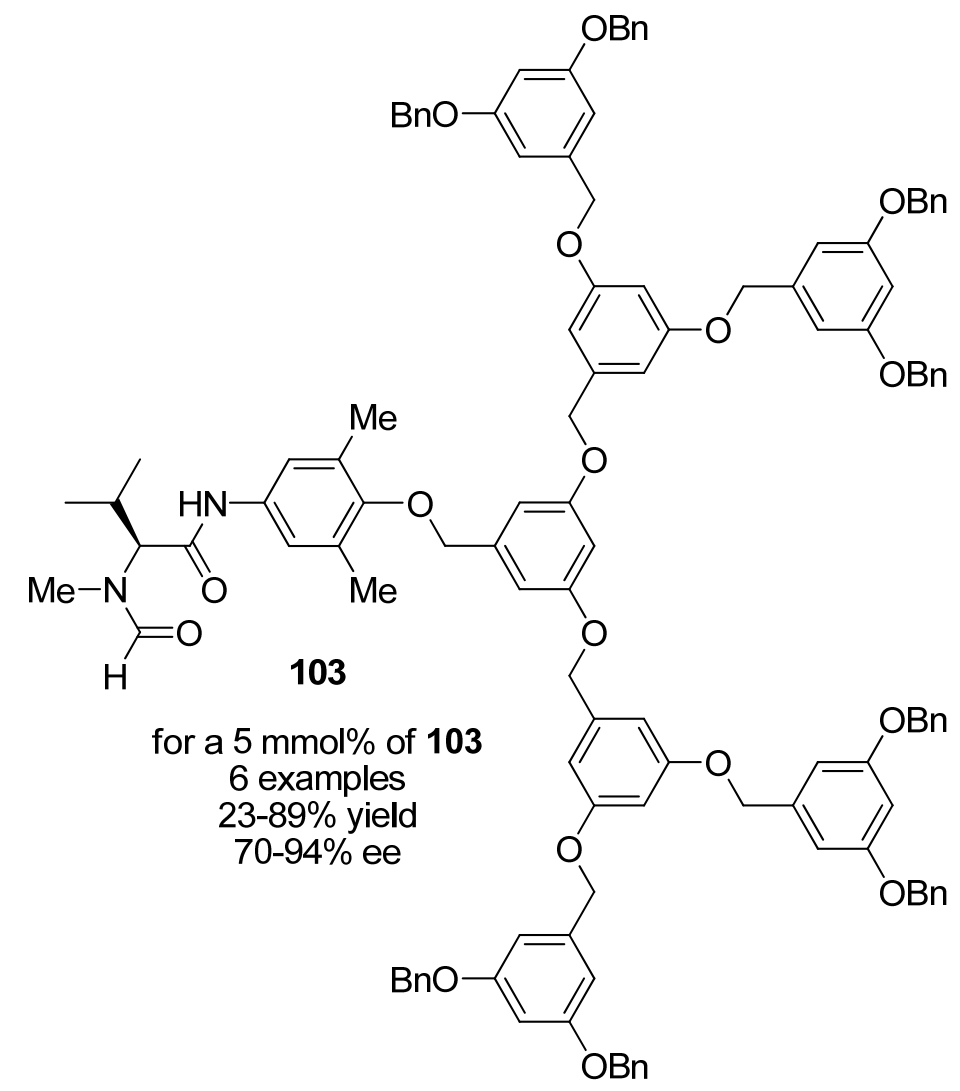

Figure 3.10 Dendron-anchored organocatalyst 103.

\subsubsection{Reduction of ketones}

Although the reduction of imines has been widely explored, as described above, the reduction of carbonyl groups has been less studied until now. Specifically, the reduction of ketones is more limited due to the low reactivity shown by these compounds. In this field, the pioneering works using trichlorosilane as reducing agent and a chiral Lewis base were reported by Matsumura and co-workers in 1999, affording low to moderate enantioselectivities.[95,96] More recently and independently, Malkov, Kočovský and co-workers[97] and Matsumura's group,[98] reported isoquinolinyloxazoline 105 and $\mathrm{N}$-formylpyrrolidine 106, respectively, as new catalysts to significantly improve the enantioselectivity of the process in comparison with the pioneering work (Scheme 3.35). 


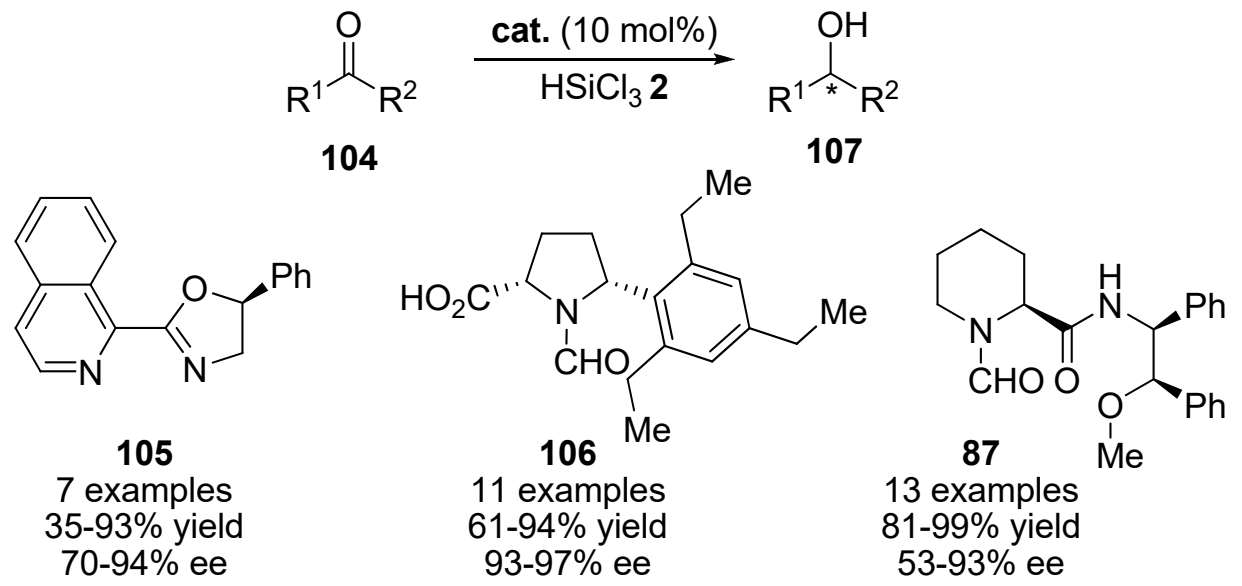

Scheme 3.35 Enantioselective reduction of ketones 104 .

In these examples the carbonyl compounds were limited to aromatic ketones. Based on the experimental results, the authors proposed the following TS to explain the enantioinduction observed in their work (Figure 3.11).[97]

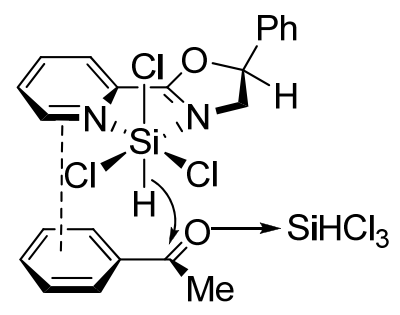

Figure 3.11 Activation proposal.

2 would be chelated by the catalyst forming an activated hydrosilylating species, while a second molecule of $\mathrm{HSiCl}_{3}$ would likely activate the ketone by coordination to the oxygen atom. The attack of the hydride would take place from the less hindered $S i$ face. Additionally, the $\pi-\pi$ interaction between the heteroaromatic ring of the catalyst and the aromatic ring in the ketone would stabilize the system.

Later, Sun's group also used their pipecolinic acid derivative $\mathbf{8 7}$ for the first efficient reduction of aliphatic and aromatic ketones with $\mathbf{2}$ in moderate to high enantioselectivity.[80] A plausible transition state was proposed in order to explain the results observed, where the catalyst 87 would act as a tridentate activator and would promote the hydrosilylation of ketones through the heptacoordinate silicon structure depicted in Figure 3.12. 


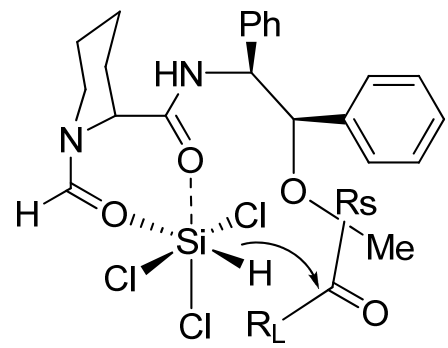

Figure 3.12 Role of pipecolinic acid derivative 87.

It is remarkable that the hydrosilylation procedure has been successfully used for the synthesis of important targets. Matsumara and co-workers demonstrated the applicability of their developed method in the preparation of optically active lactone $\mathbf{1 0 9}$ from keto ester $\mathbf{1 0 8}$ in $93 \%$ yield with 97\% ee (Scheme 3.36).[98] Lactone 109 is an important building block for the synthesis of a variety of biologically active substances.[99]

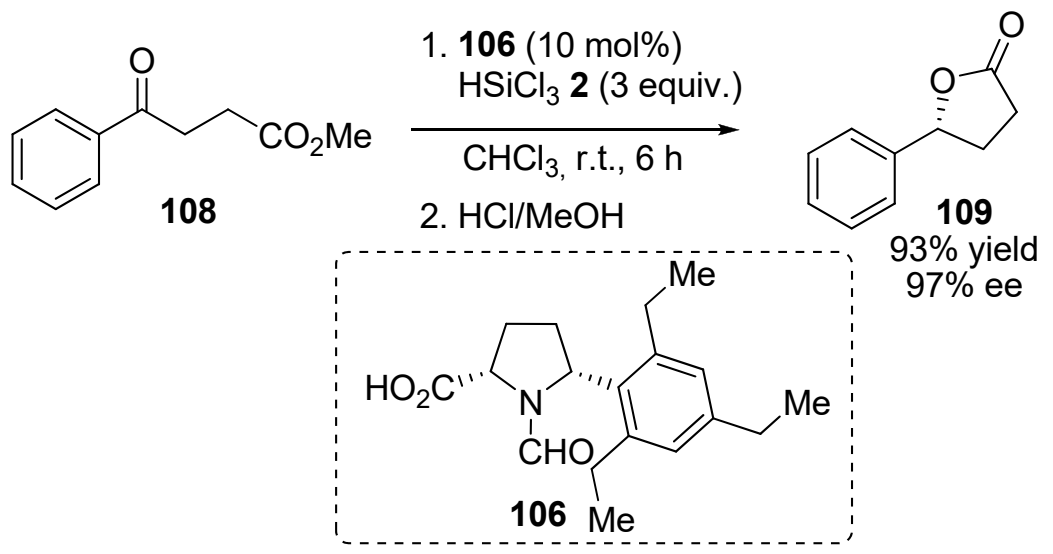

Scheme 3.36 Synthesis of optically active lactone 109.

\subsubsection{Reduction of $\beta$-enamino esters}

In the last decade, increasing efforts have been devoted to the asymmetric preparation of structurally diverse $\beta$-amino acids,[100] due to their involvement in the synthesis of peptidomimetics and as valuable building blocks.

In this field of research, enantiomerically enriched $\beta$-amino acids could be also obtained through transfer hydrogenation using $\beta$-enamino esters. $[101,102]$ This approach was initiated by Matsumura and co-workers[72a] reporting a single example using catalyst 111 (Scheme 3.37). Later, the methodology was improved by Zhang's group with Lewis base catalyst 112[103] and 113,[104] and also Benaglia and co-workers with catalysts 114 (Scheme 3.37).[105] 
Remarkably, Sun's group reported an interesting methodology using water as additive and the Lewis base catalyst 115.[106] The addition of 1 equiv. of water resulted to be crucial for the success of both reactivity and enantioselectivity of the process (Scheme 3.37). All these approaches were potentially useful for the preparation of enantiomerically enriched $\beta$-amino acid derivatives, which in all cases were achieved with good yield and good enantioselectivies.[107]<smiles>[R]C(NNC(=O)O)=C([Y9]=O)C(=O)OCC</smiles><smiles>[R]C(NC(=O)O)C([Y6])C(=O)OCC</smiles><smiles>O=C(c1ccccn1)N1CCCC1C(O)(c1ccccc1)c1ccccc1</smiles>

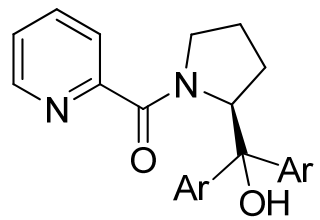
$\mathrm{Ar}=3,5-\mathrm{Me}_{2} \mathrm{C}_{6} \mathrm{H}_{3}$

111

112

for 113

for

$\begin{array}{ccc}\beta^{3} \text {-amino acids } & \beta^{3} \text {-amino acids for } X=H & \alpha \text {-acetoxy } \beta^{3} \text {-amino acids } \\ (X=H) & \beta^{2,3} \text {-amino acids for } X=\text { Alkyl } & (X=O A c) \\ 1 \text { example } & 23 \text { examples } & 15 \text { examples } \\ 65 \% \text { yield } & 82-97 \% \text { yield } & 90-98 \% \text { yield } \\ 41 \% \text { ee } & 17-96 \% \text { ee } & 41-96 \% \text { ee } \\ & \text { dr }>99: 1 & \text { synlant } \text { up to } 99: 1\end{array}$<smiles>[X][X]C(=O)P(=O)(CC1CCCN1P(=O)(c1ccccc1)c1ccccc1)c1ccccc1</smiles>

114

for

$\beta^{3}$-amino acids $(\mathrm{X}=\mathrm{H})$

10 examples

$50-99 \%$ yield

$85-21 \%$ ee<smiles>[R]c1cccc([R])c1NC(=O)C1CCCN1S(=O)C(C)(C)C</smiles>

$\beta^{3}$-amino acids $(X=H)$

19 examples

$73-98 \%$ yield

$51-97 \%$ ee

Scheme 3.37 Reduction of $\beta$-enamino esters 110.[108]

Interestingly, in order to extend the applicability of the reduction of $\beta$-enamino esters, the protocol developed by Zhang and co-workers using catalyst $\mathbf{1 1 3}$ was successfully applied in the 
synthesis of taxol C13 side chain $\mathbf{1 1 7}$ and oxazolidinone 118, which is a potent hypocholesterolemic agent (Schemes 3.38 and 3.39).[104]

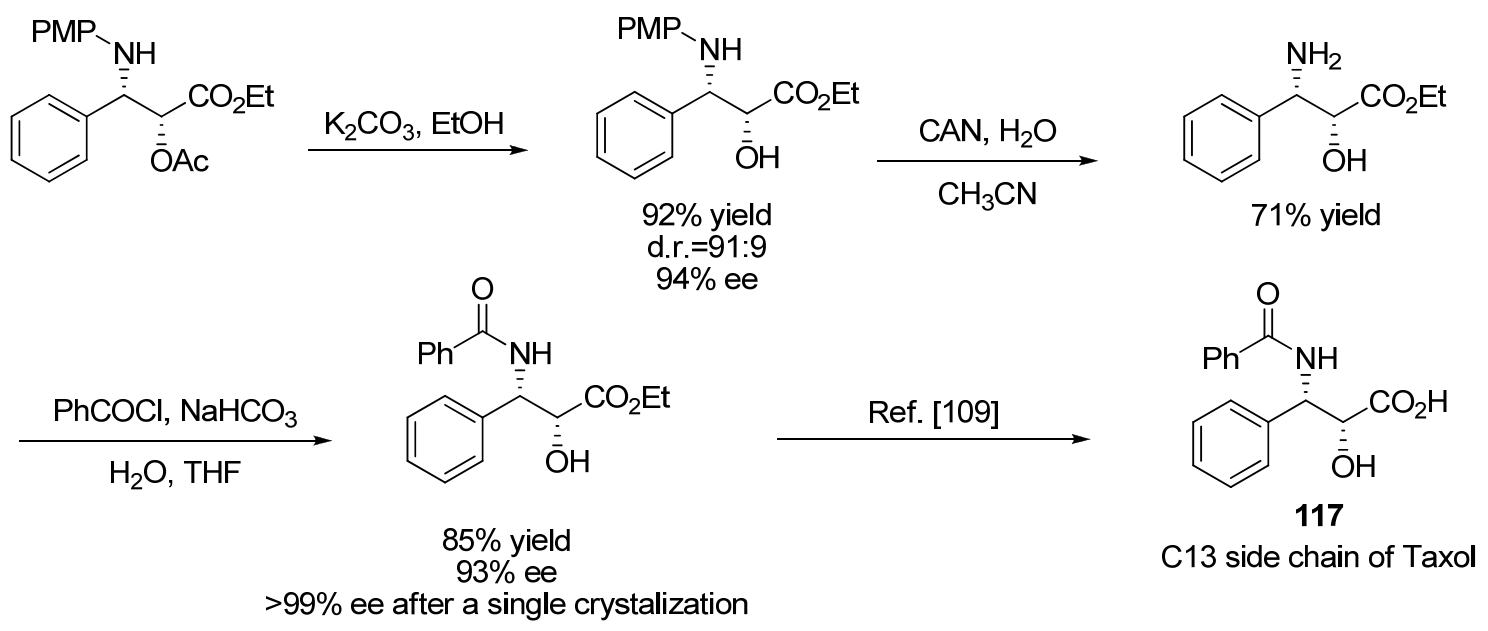

Scheme 3.38 Enantioselective synthesis of the taxol C13 side chain 117.[109]

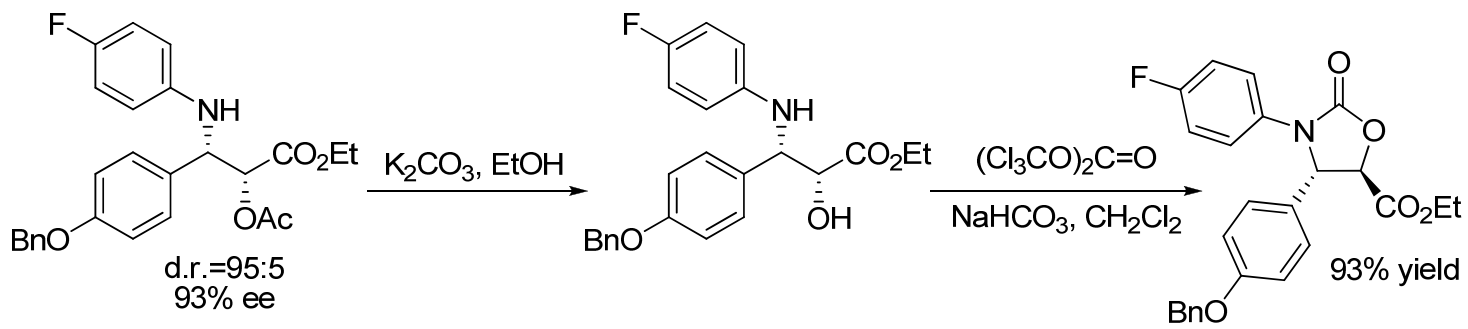

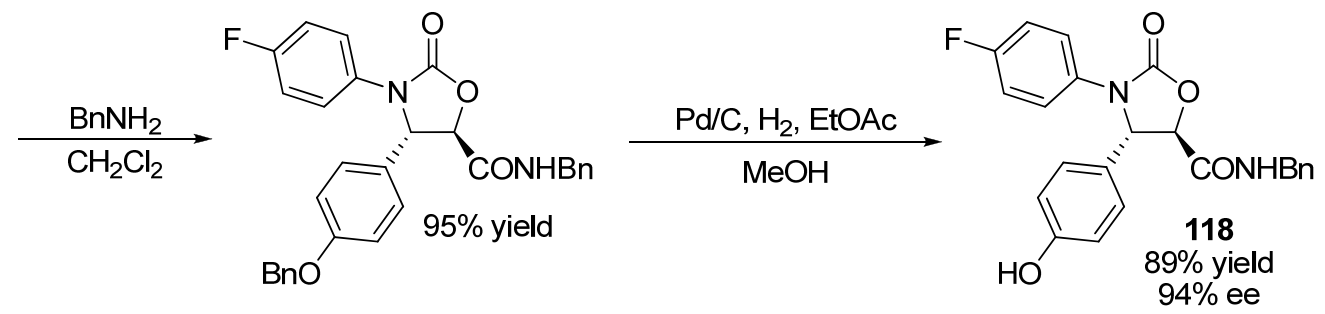

Scheme 3.39 Enantioselective synthesis of oxazolidinone 118.[110]

Malkov, Kočovský and coworkers also reported the interesting synthesis of $\beta^{2,3}$-amino acids, which synthesis is still a challenge, using organocatalyst 83 (Scheme 3.40).[111] This approach is based on the fast equilibration between the enamine and imine forms. A subsequent reduction of the equilibrated mixture with $\mathrm{HSiCl}_{3}$, afforded the corresponding amino esters and amino nitriles with good results. 


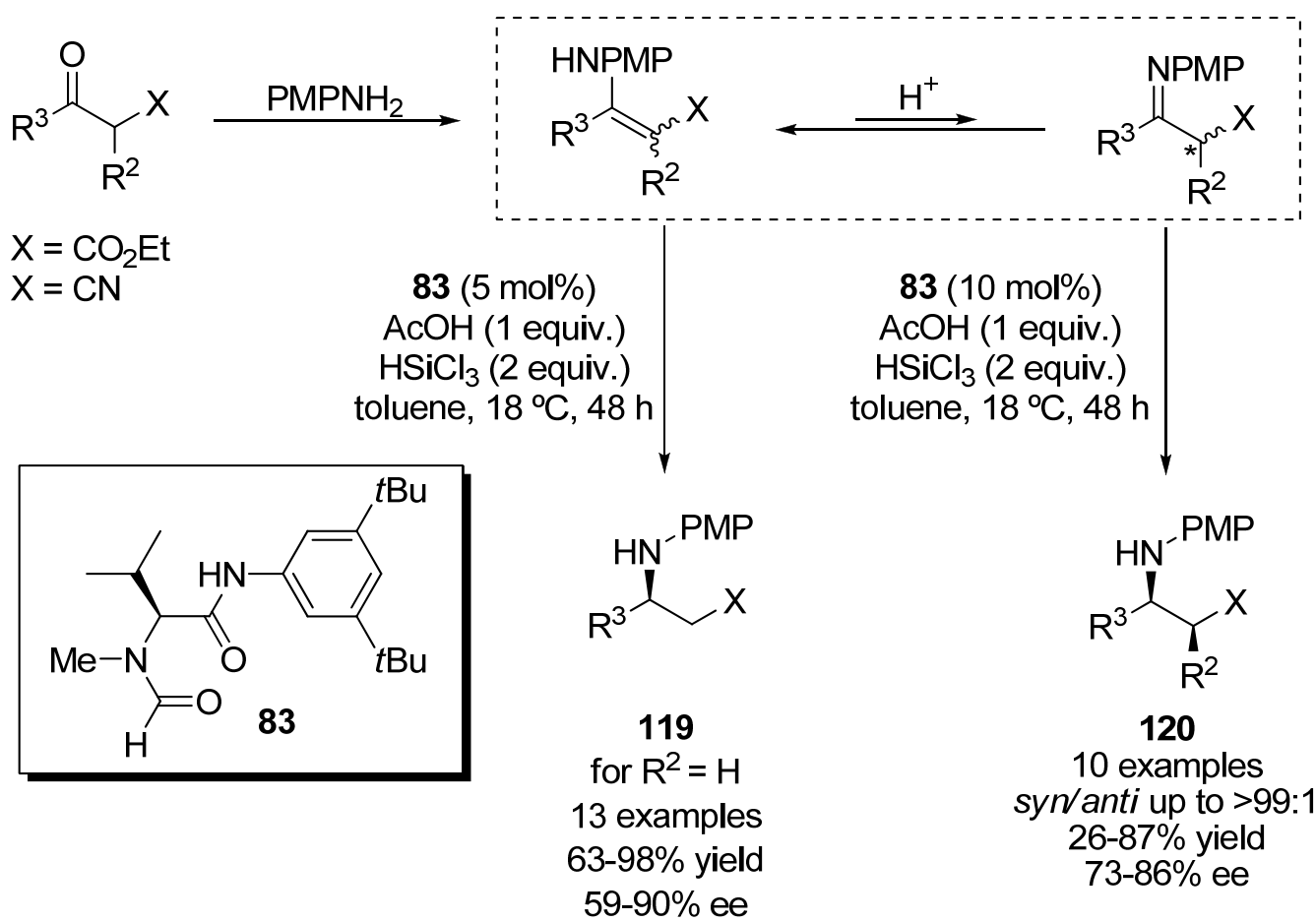

Scheme 3.40 Enantioselective synthesis of $\beta^{3}$ - and $\beta^{2,3}$-amino acid derivatives 119 and 120.

AcOH was used in order to maintain the concentration of $\mathrm{H}^{+}$constant. Although the presence of $\mathrm{H}^{+}$also catalyzed the competing nonselective reduction, under the optimized reaction conditions the use of one equivalent of $\mathrm{AcOH}$ provided a good compromise between reactivity and selectivity.

\subsection{Conclusions}

A great number of organocatalytic examples of reduction of different $\mathrm{C}=\mathrm{N}, \mathrm{C}=\mathrm{O}$ and $\mathrm{C}=\mathrm{C}$ double bonds affording to new chiral centers has been illustrated. The organocatalytic transfer hydrogenation has been mainly focused on the pioneering examples using Hantzsch dihydropyridines $\mathbf{1}$ and trichlorosilane $\mathbf{2}$ as hydride sources, although other reducing agents have being explored in the last few years. Organocatalysts such as chiral Brønsted acids, thioureas, chiral secondary amines or Lewis bases have been successfully used in all the reported examples. As reflected by the numerous examples, this field is being the focus of a great interest. This is proof of the importance that the asymmetric transfer hydrogenation arouses and the power of this approach to achieve the final target. Certainly, in the next future new hydride sources and novel organocatalysts will be designed to achieve this goal in a greener and more environmentally friendly manner. 


\subsection{References}

1 T. C. Nugent (Ed.) in Chiral Amine Synthesis. Wiley-VCH: Weinheim, 2010.

2 For reviews, see: a) S. Kobayashi, H. Ishitani, Chem. Rev. 1999, 99, 1069-1094; b) M. J. Palmer, M. Wills, Tetrahedron: Asymmetry, 1999, 10, 2045-2061; c) J.-F. Carpentier, V. Bette, Curr. Org. Chem. 2002, 6, 913-936; d) W. Tang, X. Zhang, Chem. Rev. 2003, 103, 3029-3069; e) H.-U. Blaser, C. Malan, B. Pugin, F. Spindler, H. Steiner, M. Studer, Adv. Synth. Catal. 2003, 345, 103-151; f) O. Riant, N. Mostefaï, J. Courmarcel, Synthesis 2004, 2943-2958; g) V. I. Tararov, A. Börner, Synlett 2005, 203-211; h) J. S. M. Samec, J.-E. Bäckvall, P. G. Andersson, P. Brandt, Chem. Soc. Rev. 2006, 35, 237-248; i) B. T. Cho, Tetrahedron, 2006, 62, 7621-7643. 3 a) A. Berkessel, H. Gröger, Asymmetric Organocatalysis. Wiley-VCH: Weinheim, 2005; b) P. I. Dalko, (Ed.) Enantioselective Organocatalysis. Wiley \& Sons: New York, 2007; c) P. I. Dalko, (Ed.) Comprehensive Enantioselective Organocatalysis. Wiley-VCH: Weinheim, 2013. 4 For selected reviews on organocatalytic transfer hydrogenations, see: a) H. Adolfsson, Angew. Chem. Int. Ed. 2005, 44, 3340-3342; b) R. P. Tripathi, S. S. Verma, J. Pandey, V. K. Tiwari, Curr. Org. Chem. 2008, 12, 1093-1115; c) M. Rueping, J. Dufour, F. R. Schoepke, Green Chem. 2011, 13, 1084-1105; d) C. Zheng, S.-L. You, Chem. Soc. Rev. 2012, 41, 2498-2518; e) M. Benaglia, M. Bonsignore, A. Genoni, in Stereoselective Organocatalysis: Bond Formation Methodologies and Activation Modes. R. Rios (Ed.) John Wiley \& Sons: Hoboken, 2013, pp. 529-558; f) G. Li, J. C. Antilla, in Comprehensive Enantioselective Organocatalysis. P. I. Dalko, (Ed.) Wiley-VCH: Weinheim, 2013, pp. 941-974; g) F. Kortmann, A. Minnaard, in Stereoselective Synthesis of Drugs and Natural Products. V. Andrushko, N. Andrushko (Eds.) JohnWiley \& Sons: Hoboken, 2013, pp. 993-1014.

5 For reviews, see: a) S. G. Ouellet, A. M. Walji, D. W. C. MacMillan, Acc. Chem. Res. 2007, 40, 1327-1339; b) S.-L. You, Chem. Asian J. 2007, 2, 820-827; c) S. J. Connon, Org. Biomol. Chem. 2007, 5, 3407-3417; d) C. Wang, X. Wu, J. Xiao, Chem. Asian J. 2008, 3, 1750-1770; f) M. Rueping, E. Sugiono, F. R. Schoepke, Synlett 2010, 852-865; g) L. Bernardi, M. Fochi, M. C. Franchini, A. Ricci, Org. Biomol. Chem. 2012, 10, 2911-2922. 
6 a) P. Kočovský, A. V. Malkov, in Enantioselective Organocatalysis. Reactions and Experimental Procedures. P. I. Dalko (Ed.), Wiley-VCH: Weinheim, 2007, pp. 275-278; b) P. Kočovský, S. Stončius, Chiral Amine Synthesis. T. C. Nugent (Ed.), in Wiley-VCH: Weinheim, 2010, pp. 131-156; c) S. Guizzetti, M. Benaglia, Eur. J. Org. Chem. 2010, 5529-554; d) S. Jones, C. J. A. Warner, Org. Biomol. Chem. 2012, 10, 2189-2200.

7 Benzothiazoline 3 was firstly introduced by Akiyama's group for asymmetric transfer hydrogenation reactions: a) C. Zhu, T. Akiyama, Org. Lett. 2009, 11, 4180-4183; b) T. Sakamoto, K. Mori, T. Akiyama, Org. Lett. 2012, 14, 3312-3315.

8 C. Zhu, K. Saito, M. Yamanaka, T. Akiyama, Acc. Chem. Res. 2015, 48, 388-398.

9 S. Rossi, M. Benaglia, E. Massolo, L. Raimondi, Catal. Sci. Technol. 2014, 4, 2708-2723.

10 a) A. Hantzsch, Ber. 1881, 14, 1637-1638; b) A. Hantzsch, Justus Liebigs Ann. Chem. 1882, $215,1-82$.

11 S. Singh, U. K. Batra, Ind. J. Chem., Sect. B. 1989, 28, 1-2.

12 For earlier examples on the transfer hydrogenation of imines with Hantzsch esters 1: a) J. B. Steevens, U. K. Pandit, Tetrahedron 1983, 39, 1395-1400; b) M. Fujii, T. Aida, M. Yoshihara, A. Ohno, Bull. Chem. Soc. Jpn. 1989, 62, 3845-3847; c) T. Itoh, K. Nagata, A. Kurihara, M. Miyazaki, A. Ohsawa, Tetrahedron Lett. 2002, 43, 3105-3108.

13 M. Rueping, E. Sugiono, C. Azap, T. Theissmann, M. Bolte, Org. Lett. 2005, 7, 3781-3783. 14 S. Hoffmann, A. M. Seayad, B. List, Angew. Chem. Int. Ed. 2005, 44, 7424-7427.

15 T. Itoh, K. Nagata, M. Miyazaki, H. Ishikawa, A. Kurihara, A. Ohsawa, Tetrahedron 2004, $60,6649-6655$.

16 M. Rueping, C. Azap, E. Sugiono, T. Theissmann, Synlett 2005, 2367-2369.

17 For reviews about chiral phosphoric acid catalysis, see: a) T. Akiyama, Chem. Rev. 2007, 107, 5744-5758; b) M. Terada, Chem. Commun. 2008, 4097-4112; c) G. Adair, S. Mukherjee, B. List, Aldrichim. Acta 2008, 41, 31-39; d) S.-L. You, Q. Cai, M. Zeng, Chem. Soc. Rev. 2009, 38, 2190-2201; e) D. Kampen, C. M. Reisinger, B. List, Top. Curr. Chem. 2010, 291, 395-456; f) M. Terada, Synthesis 2010, 1929-1982; g) M. Terada, Bull. Chem. Soc. Jpn. 2010, 83, 101- 
119; h) J. Yu, F. Shi, L.-Z. Gong, Acc. Chem. Res. 2011, 44, 1156-1171; i) M. Terada, Curr. Org. Chem. 2011, 15, 2227-2256; j) M. Rueping, A. Kuenkel, I. Atodiresei, Chem. Soc. Rev. 2011, 40, 4539-4549; k) S. Schenker, A. Zamfir, M. Freund, S. B. Tsogoeva, Eur. J. Org. Chem. 2011, 2209-2222; 1) I. Čorić, S. Vellalath, S. Müller, X. Cheng, B. List, Top. Organomet. Chem. 2013, 44, 165-194; m) D. Parmar, E. Sugiono, S. Raja, M. Rueping, Chem. Rev. 2014, 114, 9047-9153; n) F. E. Held, D. Grau, S. B. Tsogoeva, Molecules 2015, 20, 16103-16126.

18 For mechanistic studies of this reaction, see: a) T. Marcelli, P. Hammar, F. Himo, Chem. Eur. J. 2008, 14, 8562- 8571; b) L. Simón, J. M. Goodman, J. Am. Chem. Soc. 2008, 130, 87418747; c) T. Marcelli, P. Hammar, F. Himo, Adv. Synth. Catal. 2009, 351, 525-529.

19 R. I. Storer, D. E. Carrera, Y. Ni, D. W. C. MacMillan, J. Am. Chem. Soc. 2006, 128, 84-86. 20 It is important to remark that as declared by the authors, the complete details of MacMillan's group concerning reductive amination were first published via oral presentation in August 2005 in presentations in Germany, Wales, Japan, and the USA prior to submission of their manuscript on this field (October 23rd, 2005). See ref. 5a.

21 Q. Kang, Z.-A. Zhao, S.-L. You, Adv. Synth. Catal. 2007, 349, 1657-1660.

22 Q. Kang, Z.-A. Zhao, S.-L. You, Org. Lett. 2008, 10, 2031-2034.

23 G. Li, Y. Liang, J. C. Antilla, J. Am. Chem. Soc. 2007, 129, 5830-5831.

24 M. Rueping, A. P. Antonchick, T. Theissmann, Angew. Chem. Int. Ed. 2006, 45, 3683-3686. 25 A. R. Katritzky, S. Rachwal, B. Rachwal, Tetrahedron 1996, 52, 15031-15070.

26 a) J. H. Rakotoson, N. Fabre, I. Jacquemond-Collet, S. Hannedouche, I. Fouraste, C. Moulis, Planta Med. 1998, 64, 762-763; b) I. Jacquemond-Collet, S. Hannedouche, N. Fabre, I. Fouraste, C. Moulis, Phytochem. 1999, 51, 1167-1169.

27 P. J. Houghton, T. Z. Woldemariam, Y. Watanabe, M. Yates, Planta Med. 1999, 65, 250254.

28 For a report on the achiral transfer hydrogenation of differently substituted quinolines, see also: M. Rueping, T. Theissmann, A. P. Antonchick, Synlett 2006, 1071-1074. 
29 For similar methodologies as extension of this approach, see: a) M. Rueping, T. Theissmann, S. Raja, J. W. Bats, Adv. Synth. Catal. 2008, 350, 1001-1006; b) Q.-S. Guo, D.-M. Du, J. Xu, Angew. Chem. Int. Ed. 2008, 47, 759-762; c) C. Metallinos, F. B. Barrett, S. Xu, Synlett 2008, 720-724; d) Z.-Y. Han, H. Xiao, X.-H. Chen, L.-Z. Gong, J. Am. Chem. Soc. 2009, 131, 91829183; e) M. Rueping, E. Sugiono, A. Steck, T. Theissmann, Adv. Synth. Catal. 2010, 352, 281287; f) M. Rueping, T. Theissmann, Chem. Sci. 2010, 1, 473-476; g) M. Rueping, T. Theissmann, M. Stoeckel, A. P. Antonchick, Org. Biomol. Chem. 2011, 9, 6844-6850; For transfer hydrogenation of 1,2-dihydroquinolines, see: h) G. Li, H. Liu, G. Lv, Y. Wang, Q. Fu, Z. Tang, Org. Lett. 2015, 17, 4125-4127.

30 For examples of dual catalysis, see: a) X.-F. Tu, L.-Z. Gong, Angew. Chem. Int. Ed. 2012, 51, 11346-11349; b) F. Shi, L.-Z. Gong, Angew. Chem. Int. Ed. 2012, 51, 11423-11425.

31 For more recent examples, see: a) M.-W. Chen, X.-F. Cai, Z.-P. Chen, L. Shi, Y.-G. Zhou, Chem. Commun. 2014, 50, 12526-12529; b) R.-N. Guo, Z.-P. Chen, X.-F. Cai, Y.-G. Zhou, Synthesis 2014, 46, 2751-2756; c) A. Aillerie, V. L. de Talancé, A. Moncomble, T. Bousquet, L. Pélinski, Org. Lett. 2014, 16, 2982-2985.

32 a) I. Hayakawa, S. Atarashi, S. Yokohama, M. Imamura, K.-I. Sakano, M. Furukawa, Antimicrob. Agents Chemother. 1986, 29, 163-164; b) D. Seiyaku, Drugs Future 1992, 17, 559563.

33 M. Rueping, M. Stoeckel, E. Sugiono, T. Theissmann, Tetrahedron 2010, 66, 6565-6568.

34 a) P. Friedländer, Ber. Dtsch. Chem. Ges. 1882, 15, 2572-2575; b) J. Marco-Contelles, E. Pérez-Mayoral, A. Samadi, M. C. Carreiras, E. Soriano, Chem. Rev. 2009, 109, 2652-2671.

35 L. Ren, T. Lei, J.-X. Ye, L.-Z. Gong, Angew. Chem. Int. Ed. 2012, 51, 771-774.

36 M. Rueping, A. P. Antonchick, Angew. Chem. Int. Ed. 2007, 46, 4562-4565.

37 a) F. Bohlmann, D. Rahtz, Chem. Ber. 1957, 90, 2265-2272; b) M. C. Bagley, C. Brace, J. W. Dale, M. Ohnesorge, N. G. Phillips, X. Xiong, J. Bower, J. Chem. Soc. Perkin Trans. 1 2002, 1663-1671. 
38 H. M. Sklenicka, R. P. Hsung, M. J. McLaughlin, L.-L. Wie, A. I. Gerasyuto, W. B. Brennessel, J. Am. Chem. Soc. 2002, 124, 10435-10442.

39 M. Rueping, A. P. Antonchick, T. Theissmann, Angew. Chem. Int. Ed. 2006, 45, 6751-6755. 40 a) L. F. Tietze, G. Brasche, K. M. Gericke, (Eds.) Domino Reactions in Organic Synthesis, Wiley-VCH: Weinheim, 2006; b) D. Enders, C. Grondal, M. R. M. Hüttl, Angew. Chem. Int. Ed. 2007, 46, 1570-1581; c) A. M. Walji, D. W. C. MacMillan, Synlett 2007, 1477-1489.

41 M. Rueping, A. P. Antonchick, Angew. Chem. Int. Ed. 2008, 45, 5836-5838.

42 M. Rueping, F. Tato, F. R. Schoepke, Chem. Eur. J. 2010, 16, 2688-2691.

43 a) M. Fantin, M. Marti, Y. P. Auberson, M. Morari, J. Neurochem. 2007, 103, 2200-2211; b)

R. E. TenBrink, W. B. Im, V. H. Sethy, A. H. Tang, D. B. Carter, J. Med. Chem. 1994, 37, 758768; c) S. Li, X. Tian, D. M. Hartley, L. A. Feig, J. Neurosci. 2006, 26, 1721-1729; d) M. Patel, R. J. McHush, Jr., B. C. Cordova, R. M. Klabe, S. Erickson-Viitanen, G. L. Trainor, J. D. Rodgers, Bioorg. Med. Chem. Lett. 2000, 10, 1729-1731.

44 F. Shi, W. Tan, H.-H. Zhang, M. Li, Q. Ye, G.-H. Ma, S.-J. Tu, G. Li, Adv. Synth. Catal. 2013, 355, 3715-3726.

45 a) H.-H. Liao, C.-C. Hsiao, E. Sugiono, M. Rueping, Chem. Commun. 2013, 49, 7953-7955;

b) E. Sugiono, M. Rueping, Beilstein J. Org. Chem. 2013, 9, 2457-2462.

46 C.-C. Hsiao, H.-H. Liao, E. Sugiono, I. Atodiresei, M. Rueping, Chem. -Eur. J. 2013, 19, 9775-9779.

47 Z. Wang, F. Ai, Z. Wang, W. Zhao, G. Zhu, Z. Lin, J. Sun, J. Am. Chem. Soc. 2015, 137, 383-389.

48 For selected reviews concerning aminocatalysis field, see: a) P. I. Dalko, L. Moisan, Angew. Chem. Int. Ed. 2004, 43, 5138-5175; b) J. Seayed, B. List, Org. Biomol. Chem. 2005, 3, 719724; c) B. List, Chem. Commun. 2006, 819-824; d) M. Marigo, K. A. Jørgensen, Chem. Commun. 2006, 2001-2011; e) G. Guillena, D. J. Ramón, Tetrahedron: Asymmetry 2006, 17, 1465-1492; f) S. Sulzer-Mossé, A. Alexakis, Chem. Commun. 2007, 3123-3135; g) S. B. Tsogoeva, Eur. J. Org. Chem. 2007, 1701-1716; h) J. L. Vicario, D. Badía, L. Carrillo, 
Synthesis 2007, 2065-2092; i) D. Almaşi, D. A. Alonso, C. Najera, Tetrahedron: Asymmetry 2007, 18, 299-365; j) H. Pellissier, Tetrahedron 2007, 63, 9267-9331; k) A. Dondoni, A. Massi, Angew. Chem. Int. Ed. 2008, 47, 4638-4660; 1) P. Melchiorre, M. Marigo, A. Carlone, G. Bartoli, Angew. Chem. Int. Ed. 2008, 47, 6138-6171; m) M. Gruttadauria, F. Giacalone, R. Noto, Adv. Synth. Catal. 2009, 351, 33-57; n) S. Bertelsen, K. A. Jørgensen, Chem. Soc. Rev. 2009, 38, 2178-2189; o) M. Ueda, T. Kano, K. Maruoka, Org. Biomol. Chem. 2009, 7, $2005-$ 2012; p) M. Nielsen, C. B. Jacobsen, N. Holub, M. W. Paixão, K. A. Jørgensen, Angew. Chem. Int. Ed. 2010, 49, 2668-2679; q) M. Nielsen, D. Worgull, T. Zweifel, B. Gschwend, S. Bertelsen, K. A. Jørgensen, Chem. Commun. 2011, 47, 632-649; r) E. Marqués-López, R. P. Herrera, Curr. Org. Chem. 2011, 15, 2311-2327; s) I. D. Jurberg, I. Chatterjee, R. Tannert, P. Melchiorre, Chem. Commun. 2013, 49, 4869-4883; t) B. M. Paz, H. Jiang, K. A. Jørgensen, Chem. Eur. J. 2015, 21, 1846-1853.

49 J. W. Yang, M. T. H. Fonseca, B. List, Angew. Chem. Int. Ed. 2004, 43, 6660-6662.

50 J. W. Yang, M. T. H. Fonseca, N. Vignola, B. List, Angew. Chem. Int. Ed. 2005, 44, 108110.

51 S. G. Ouellet, J. B. Tuttle, D.W. C. MacMillan, J. Am. Chem. Soc. 2005, 127, 32-33.

52 As reported by the authors in ref. $5 \mathrm{a}$, the complete details of their studies into transfer hydrogenation were first published via oral presentation on March 1st, 2003, at the Eli Lilly Young Award symposium, Indianapolis. Their work was further communicated in $>15$ presentations in Europe, USA, Australia, and Asia prior to submission of their manuscript (October 10th, 2004).

53 J. B. Tuttle, S. G. Ouellet, D. W. C. MacMillan, J. Am. Chem. Soc. 2006, 128, 12662-12663. 54 For an application of this methodology by the same research group, see: Y. Huang, A. M. Walji, C. H. Larsen, D. W. C. MacMillan, J. Am. Chem. Soc. 2005, 127, 15051-15053.

55 S. Mayer, B. List, Angew. Chem., Int. Ed. 2006, 45, 4193-4195.

56 N. J. A. Martin, B. List, J. Am. Chem. Soc. 2006, 128, 13368-13369.

57 S. T.-C. Eey, M. J. Lear, Org. Lett. 2010, 12, 5510-5513. 
58 For further studies in this field, see also: a) K. Akagawa, H. Akabane, S. Sakamoto, K. Kudo, Org. Lett. 2008, 10, 2035-2037; b) K. Akagawa, H. Akabane, S. Sakamoto, K. Kudo, Tetrahedron: Asymmetry 2009, 20, 461-466; c) T. J. Hoffman, J. Dash, J. H. Rigby, S. Arseniyadis, J. Cossy, Org. Lett. 2009, 11, 2756-2759.

59 For pivotal reviews concerning chiral thioureas, see: a) P. R. Schreiner, Chem. Soc. Rev. 2003, 32, 289-296; b) Y. Takemoto, Org. Biomol. Chem. 2005, 3, 4299-4306; c) J. A. J. Breuzard, M. L. Christ-Tommasino, M. Lemaire, Top Organomet. Chem. 2005, 15, 231-270; d) S. J. Connon, Chem. Eur. J. 2006, 12, 5418-5427; e) M. S. Taylor, E. N. Jacobsen, Angew. Chem. Int. Ed. 2006, 45, 1520-1543; f) A. G. Doyle, E. N. Jacobsen, Chem. Rev. 2007, 107, 5713-5743; g) Z. Zhang, P. R. Schreiner, Chem. Soc. Rev. 2009, 38, 1187-1198; h) E. MarquésLópez, R. P. Herrera, An. Quim. 2009, 105, 5-12; i) M. Kotke, P. R. Schreiner, in Hydrogen Bonding in Organic Synthesis, P. M. Pihko (Ed.), Wiley-VCH: Weinheim, 2009, pp. 141-351; j) S. J. Connon, Synlett 2009, 354-376; k) E. Marqués-López, R. P. Herrera, in New Strategies in Chemical Synthesis and Catalysis, B. Pignataro (Ed.), Wiley-VCH: Weinheim, 2012, pp 175199; 1) S. Narayanaperumal, D. G. Rivera, R. C. Silva, M. W. Paixão, ChemCatChem 2013, 5, 2756-2773; m) G. Jakab, P. R. Schreiner in Comprehensive Enantioselective Organocatalysis, P. Dalko (Ed.), Wiley-VCH: Weinheim, 2013, pp 315-341; n) O. V. Serdyuk, C. M. Heckel, S. B. Tsogoeva, Org. Biomol. Chem. 2013, 11, 7051-7071.

60 For the pioneering use of non-chiral thioureas in a transfer-hydrogenation reaction, see: D. Menche, F. Arikan, Synlett 2006, 841-844.

61 N. J. A. Martin, L. Ozores, B. List, J. Am. Chem. Soc. 2007, 129, 8976-8977.

62 For the non-enantioselective version of this reaction, see: Z. Zhang, P. R. Schreiner, Synthesis 2007, 2559-2564.

63 N. J. A. Martin, X. Cheng, B. List, J. Am. Chem. Soc. 2008, 130, 13862-13863.

64 For other developed methods of asymmetric transfer hydrogenation of nitroolefins using thioureas, see: a) J. F. Schneider, F. C. Falk, R. Fröhlich, J. Paradies, Eur. J. Org. Chem. 2010, 
2265-2269; b) J. F. Schneider, M. B. Lauber, V. Muhr, D. Kratzer, J. Paradies, Org. Biomol. Chem. 2011, 9, 4323-4327.

65 E. Massolo, M. Benaglia, M. Orlandi, S. Rossi, G. Celentano, Chem. Eur. J. 2015, 21, 35893595.

66 E. Martinelli, A. C. Vicini, M. Mancinelli, A. Mazzanti, P. Zani, L. Bernardi, M. Fochi, Chem. Commun. 2015, 51, 658-660.

67 For the activation of trichlorosilyl reagents by Lewis bases, see also: a) S. E. Denmark, J. Fu, Chem. Rev. 2003, 103, 2763-2793; b) S. E. Denmark, G. L. Beutner, Angew. Chem. Int. Ed. 2008, $47,1560-1638$.

68 F. Iwasaki, O. Onomura, K. Mishima, T. Kanematsu, T. Maki, Y. Matsumura, Tetrahedron Lett. 2001, 42, 2525-2527.

69 C. Baudequin, D. Chaturvedi, S. B. Tsogoeva, Eur. J. Org. Chem. 2007, 2623-2629.

70 Z.-Y. Xue, Y. Jiang, W.-C. Yuan, X.-M. Zhang, Eur. J. Org. Chem. 2010, 616-619.

71 For the use of additional picolinoyl catalyst derivatives, see also: a) H. Zheng, J. Deng, W. Lin, X. Zhang, Tetrahedron Lett. 2007, 48, 7934-7937; b) Z.-Y. Xue, Y. Jiang, X.-Z. Peng, W.C. Yuan, X.-M. Zhang, Adv. Synth. Catal. 2010, 352, 2132-2136; c) X. Chen, Y. Zheng, C. Shu, W. Yuan, B. Liu, X. Zhang, J. Org. Chem. 2011, 76, 9109-9115; d) A. Genoni, M. Benaglia, E. Massolo, S. Rossi, Chem. Commun. 2013, 49, 8365-8367; e) P. C. Barrulas, A. Genoni, M. Benaglia, A. J. Burke, Eur. J. Org. Chem. 2014, 7339-7342.

72 For other pyrrolidine derivatives, see: a) O. Onomura, Y. Kouchi, F. Iwasaki, Y. Matsumura, Tetrahedron Lett. 2006, 47, 3751-3754; b) Z. Wang, S. Wei, C. Wang, J. Sun, Tetrahedron: Asymmetry 2007, 18, 705-709; c) T. Kanemitsu, A. Umehara, R. Haneji, K. Nagata, T. Itoh, Tetrahedron 2012, 68, 3893-3898.

73 A. V. Malkov, A. Mariani, K. N. MacDougall, P. Kočovský, Org. Lett. 2004, 6, 2253-2256. 74 A. V. Malkov, S. Stončius, K. N. MacDougall, A. Mariani, G. D. McGeoch, P. Kočovský, Tetrahedron 2006, 62, 264-284.

75 A. V. Malkov, M. Figlus, S. Stončius, P. Kočovský, J. Org. Chem. 2007, 72, 1315-1325. 
76 a) Malkov, A. V.; Stončius, S.; Kočovský, P. Angew. Chem. Int. Ed. 2007, 46, 3722-3724; b) A. V. Malkov, K. Vranková, S. Stončius, P. Kočovský, J. Org. Chem. 2009, 74, 5839-5849.

77 A. V. Malkov, K. Vranková , R. C. Sigerson, S. Stončius, P. Kočovský, Tetrahedron 2009, $65,9481-9486$.

78 X. Ge, C. Qian, X. Chen, Tetrahedron: Asymmetry 2014, 25, 1450-1455.

79 Z. Wang, X. Ye, S. Wei, P. Wu, A. Zhang, J. Sun, Org. Lett. 2006, 8, 999-1001.

80 L. Zhou, Z. Wang, S. Wei, J. Sun, Chem. Commun. 2007, 2977-2979.

81 J. F. Collados, M. L. Quiroga-Feijóo, C. Alvarez-Ibarra, Eur. J. Org. Chem. 2009, $3357-$ 3367.

82 For more recent L-pipecolinic basic organocatalysts for hydrosilylation of imines, see: a) Y.C. Xiao, C. Wang, Y. Yao, J. Sun, Y.-C. Chen, Angew. Chem. Int. Ed. 2011, 50, 10661-10664; b) Z. Y. Wang, C. Wang, L. Zhou, J. Sun, Org. Biomol. Chem. 2013, 11, 787-797.

83 a) Z. Wang, M. Cheng, P. Wu, S. Wei, J. Sun, Org. Lett. 2006, 8, 3045-3048; b) P. Wu, Z. Wang, M. Cheng, L. Zhou, J. Sun, Tetrahedron 2008, 64, 11304-11312.

84 a) J. A. Ellman, T. D. Owens, T. P. Tang, Acc. Chem. Res. 2002, 35, 984-995; b) I. Fernandez, N. Khiar, Chem. Rev. 2003, 103, 3651-3705; c) J. A. Ellman, Pure Appl. Chem. 2003, 75, 39-46; d) P. Zhou, B.-C. Chen, F. A. Davis, Tetrahedron 2004, 60, 8003-8030; e) C. H. Senanayake, D. Krishnamurthy, Z.-H. Lu, Z. Han, I. Gallou, Aldrichim. Acta 2005, 38, 93104; f) D. Morton, R. A. Stockman, Tetrahedron 2006, 62, 8869-8905.

85 D. Pei, Z. Wang, S. Wei, Y. Zhang, J. Sun, Org. Lett. 2006, 8, 5913-5915.

86 D. Pei, Y. Zhang, S. Wei, M. Wang, J. Sun, Adv. Synth. Catal. 2008, 350, 619-623.

87 C. Wang, X. Wu, L. Zhou, J. Sun, Chem. Eur. J. 2008, 14, 8789-8792.

88 For more recent examples belonging to the same research group, see also: a) X.-W. Liu, C. Wang, Y. Yan, Y.-Q. Wang, J. Sun, J. Org. Chem. 2013, 78, 6276-6280; b) C. Wang, X. Wu, L. Zhou, J. Sun, Org. Biomol. Chem. 2015, 13, 577-582.

89 For reviews on polymer-supported organocatalysts, see: a) M. Benaglia, A. Puglisi, F. Cozzi, Chem. Rev. 2003, 103, 3401-3429; b) F. Cozzi, Adv. Synth. Catal. 2006, 348, 1367-1390; c) T. 
E. Kristensen, T. Hansen, Eur. J. Org. Chem. 2010, 3179-3204; d) T. E. Kristensen, T. Hansen in Comprehensive Enantioselective Organocatalysis. P. I. Dalko, (Ed.) Wiley-VCH: Weinheim, 2013, pp 651-672.

90 For a more recent example, see also: X. Ge, C. Qian, X. Yea, X. Chen, $R S C A d v .2015,5$, 65402-65407.

91 A. V. Malkov, M. Figlus, P. Kočovský, J. Org. Chem. 2008, 73, 3985-3996.

92 A. V. Malkov, M. Figlus, M. R. Prestly, G. Rabani, G. Cooke, P. Kočovský, Chem. Eur. J. 2009, 15, 9651-9654.

93 For the preparation of other immobilized catalysts easily recoverable, see: A. V. Malkov, M. Figlus, G. Cooke, S. T. Caldwell, G. Rabani, M. R. Prestly, P. Kočovský, Org. Biomol. Chem. 2009, 7, 1878-1883.

94 M. Figlus, S. T. Caldwell, D. Walas, G. Yesilbag, G. Cooke, P. Kočovský, A. V. Malkov, A. Sanyal, Org. Biomol. Chem. 2010, 8, 137-141.

95 For the seminal enantioselective work using Lewis base to reduce carbonyl groups, see : F. Iwasaki, O. Onomura, K. Mishima, T. Maki, Y. Matsumura, Tetrahedron Lett. 1999, 40, 75077511.

96 For pioneering works using chiral lithium salts, see: a) D. Pini, A. Iuliano, P. Salvadori, Tetrahedron: Asymmetry 1992, 3, 693-694; b) R. Schiffers, H. B. Kagan, Synlett 1997, $1175-$ 1178; c) F. J. LaRonde, M. A. Brook, Tetrahedron Lett. 1999, 40, 3507-3510.

97 A. V. Malkov, A. J. P. S. Liddon, P. Ramírez-López, L. Bendová, D. Haigh, P. Kočovský, Angew. Chem. Int. Ed. 2006, 45, 1432-1435.

98 Y. Matsumura, K. Ogura, Y. Kouchi, F. Iwasaki, O. Onomura, Org. Lett. 2006, 8, 37893792.

99 a) H. C. Brown, S. V. Kulkarni, U. S. Racherla, J. Org. Chem. 1994, 59, 365-369; b) J. W. Hilborn, Z.-H. Lu, A. R. Jurgens, Q. K. Fang, P. Byers, S. A. Wald, C. H. Senanayake, Tetrahedron Lett. 2001, 42, 8919-8921; c) A. Kamal, M. Sandbhor, A. A. Shaik, Tetrahedron: Asymmetry 2003, 14, 1575-1580. 
100 For selected reviews, see: a) D. L. Steer, R. A. Lew, P. Perlmutter, A. I. Smith, M.-I. Aguilar, Curr. Med. Chem. 2002, 9, 811- 822; b) E. Juaristi, V. A. Soloshonok, Enantioselective Synthesis of $\beta$-Amino Acids, Wiley-VCH: Hoboken, 2005; c) B. E. Sleebs, T. T. Van Nguyen, A. B. Hughes, Org. Prep. Proced. Int. 2009, 41, 429-478; d) B. Weiner, W. Szymański, D. B. Janssen, A. J. Minnaard, B. L. Feringa, Chem. Soc. Rev. 2010, 39, 1656-1691.

101 A. Weickgenannt, M. Oestreich, ChemCatChem 2011, 3, 1527-1529.

102 For pioneering works using metals, see: a) Y. Hsiao, N. R. Rivera, T. Rosner, S. W. Krska, E. Njolito, F. Wang, Y. Sun, J. D. Armstrong III, E. J. J. Grabowski, R. D. Tillyer, F. Spindler, C. Malan, J. Am. Chem. Soc. 2004, 126, 9918-9919; b) Q. Dai, W. Yang, X. Zhang, Org. Lett. 2005, 7, 5343-5345.

103 H.-J. Zheng, W.-B. Chen, Z.-J. Wu, J.-G. Deng, W.-Q. Lin, W.-C. Yuan, X.-M. Zhang, Chem. Eur. J. 2008, 14, 9864-9867.

104 Y. Jiang, X. Chen, Y. Zheng, Z. Xue, C. Shu, W. Yuan, X. Zhang, Angew. Chem. Int. Ed. 2011, 50, 7304-7307.

105 M. Bonsignore, M. Benaglia, R. Annunziata, G. Celentano, Synlett 2011, 1085-1088.

106 X. Wu, Y. Li, C. Wang, L. Zhou, X. Lu, J. Sun, Chem. Eur. J. 2011, 17, 2846-2848.

107 M. Sugiura, M. Kumahara, M. Nakajima, Chem. Commun. 2009, 3585-3587.

108 For other examples of reduction of enamines, see: a) S. Guizzetti, M. Benaglia, M. Bonsignore, L. Raimondi, Org. Biomol. Chem. 2011, 9, 739-743; b) Y.-C. Xiao, C. Wang, Y. Yao, J. Sun, Y.-C. Chen, Angew. Chem. Int. Ed. 2011, 50, 10661-10664; c) X.-W. Liu, Y. Yan, Y.-Q. Wang, C. Wang, J. Sun, Chem. Eur. J. 2012, 18, 9204-9207.

109 S. Torssell, M. Kienle, P. Somfai, Angew. Chem. Int. Ed. 2005, 44, 3096-3099.

110 M. Chrzanowska, A. Dreas, Heterocycles 2006, 69, 303-310.

111 A. V. Malkov, S. Stončius, K. Vranková, M. Arndt, P. Kočovský, Chem. Eur. J. 2008, 14, $8082-8085$. 